Please do not remove this page

RMIT

UNIVERSITY

\title{
Surface-functionalization of PDMS for potential micro-bioreactor and embryonic stem cell culture applications
}

Sarvi, Fatemeh; Yue, Zhilian; Hourigan, Kerry; Thompson, Mark; Chan, Peggy

https://researchrepository.rmit.edu.au/esploro/outputs/9921859986901341/filesAndLinks?institution=61RMIT_INST\&index=null

Sarvi, F., Yue, Z., Hourigan, K., Thompson, M., \& Chan, P. (2013). Surface-functionalization of PDMS for potential micro-bioreactor and embryonic stem cell culture applications. Journal of Materials Chemistry B, 1(7), 987-996. https://doi.org/10.1039/c2tb00019a

Document Version: Accepted Manuscript

Published Version: https://doi.org/10.1039/c2tb00019a

Repository homepage: https://researchrepository.rmit.edu.au

(c) The Royal Society of Chemistry 2013

Downloaded On 2023/04/26 18:03:07 +1000 
Thank you for downloading this document from the RMIT Research Repository.

The RMIT Research Repository is an open access database showcasing the research outputs of RMIT University researchers.

RMIT Research Repository: http://researchbank.rmit.edu.au/

\section{Citation:}

Sarvi, F, Yue, Z, Hourigan, K, Thompson, M and Chan, P 2013, 'Surface-functionalization of PDMS for potential micro-bioreactor and embryonic stem cell culture applications', Journal of Materials Chemistry B, vol. 1, no. 7, pp. 987-996.

See this record in the RMIT Research Repository at:

https://researchbank.rmit.edu.au/view/rmit:27026

Version: Accepted Manuscript

Copyright Statement: (c) The Royal Society of Chemistry 2013

Link to Published Version:

http://dx.doi.org/10.1039/c2tb00019a 


\section{RSCPublishing Journal of}

\section{Surface-functionalization of PDMS for Potential Micro- bioreactor and Embryonic Stem Cell Culture Applications}

\begin{tabular}{|r|l|}
\hline Journal: & Journal of Materials Chemistry B \\
\hline Manuscript ID: & TB-ART-08-2012-000019.R2 \\
\hline Article Type: & Paper \\
\hline Date Submitted by the Author: & $\mathrm{n} / \mathrm{a}$ \\
\hline Complete List of Authors: & $\begin{array}{l}\text { Sarvi, Fatemeh; Monash University, Mechanical \& Aerospace Engineering } \\
\text { Yue, Zhilian; University of Wollongong, Intelligent Polymer Research } \\
\text { Institute } \\
\text { Hourigan, Kerry; Monash University, Mechanical \& Aerospace Engineering } \\
\text { Thompson, Mark; Monash University, Mechanical \& Aerospace Engineering } \\
\text { Chan, Peggy; RMIT University, }\end{array}$ \\
\hline \multicolumn{2}{|l}{} \\
\hline
\end{tabular}




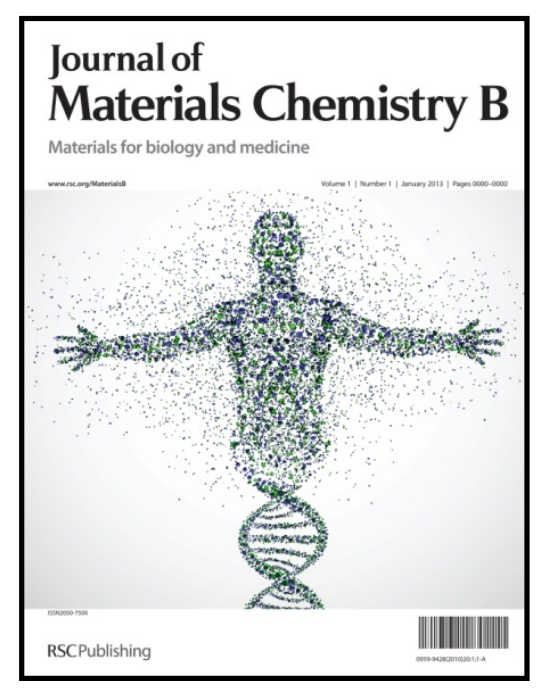

\section{Journal of Materials Chemistry B Materials for Biology and Medicine}

Full paper submission

Journal of Materials Chemistry $B$ is a weekly journal in the materials field. The journal is interdisciplinary, publishing work of international significance on all aspects of materials chemistry related to biology and medicine. Articles cover the fabrication, properties and applications of materials.

2011 Impact Factor of Journal of Materials Chemistry: 5.97

The fastest times to publication in the field

www.rsc.org/materials

The following paper has been submitted to Journal of Materials Chemistry $B$ for consideration as a full paper.

Journal of Materials Chemistry $B$ wishes to publish original research that demonstrates novelty and advance, either in the chemistry used to produce materials or in the properties/applications of the materials produced. The materials should be related to the theme of materials for biology and medicine. Work submitted that is outside of these criteria will not usually be considered for publication.

Routine or incremental work, however competently researched and reported, should not be recommended for publication if it does not meet our expectations with regard to novelty and impact.

It is the responsibility of authors to provide fully convincing evidence for the homogeneity and identity of all compounds they claim as new. Evidence of both purity and identity is required to establish that the properties and constants reported are those of the compound with the new structure claimed.

Thank you for your effort in reviewing this submission. It is only through the continued service of referees that we can maintain both the high quality of the publication and the rapid response times to authors. We would greatly appreciate if you could review this paper in two weeks. Please let us know if that will not be possible.

Once again, we appreciate your time in serving as a reviewer. To acknowledge this, the RSC offers a $\mathbf{2 5 \%}$ discount on its books: http://www.rsc.org/Shop/books/discounts.asp. Please also consider submitting your next manuscript to Journal of Materials Chemistry $B$.

Best wishes,

$$
\text { liz Davies }
$$

Liz Davies

Managing Editor, Journal of Materials Chemistry $B$ 


\title{
Surface-functionalization of PDMS for Potential Micro-bioreactor and Embryonic Stem Cell Culture Applications
}

\author{
Fatemeh Sarvi $^{a}$, Zhilian Yue ${ }^{b, c}$, Kerry Hourigan ${ }^{a}$, Mark Thompson ${ }^{a}$, and Peggy P.Y. Chan*c,d \\ Received (in $X X X, X X X)$ Xth $X X X X X X X X X 20 X X$, Accepted Xth XXXXXXXXX 20XX \\ ${ }_{5}$ DOI: 10.1039/b000000x
}

This study presents a novel and inexpensive method to prepare a disposable micro-bioreactor for stem cell expansion. The micro-bioreactor was fabricated in the form of a fixed bed bioreactor with a microchannel reactor bed. The micro-bioreactor was constructed from polydimethylsiloxane (PDMS), and the microchannel was functionalized to enable cell adhesion and resistance to bovine serum albumin protein 10 adsorption. The PDMS reactor bed surface was activated by oxygen plasma, then aminized with trimethoxysilylpropyl(polyethyleneimine), followed by grafting with carboxylmethyl cellulose (CMC) and gelatin in sequence. The functionalized PDMS surface demonstrated improved hydrophilicity and antifouling properties. The grafting of gelatin promoted cell adhesion. The functionalized surface was found to be biocompatible to MDA-MB-231 and Oct4b2 cells and was demonstrated to facilitate cell 15 proliferation. The expanded Oct $4 \mathrm{~b} 2$ cells retained their proliferation potential, undifferentiated phenotype and pluripotency.

\section{Introduction}

Embryonic stem cells (ESCs) are pluripotent cells with unlimited self-replicating ability, more importantly, they have the 20 potential to differentiate (pluripotency) into all types of cells with different functions both in vitro and in vivo ${ }^{1}$. ESCs are excellent choices of in vitro cell model for regenerative medicine, functional genomics, human developmental biology and drug discovery study. However, the use of these cells requires a readily 25 available source of stem cells and/or their differentiated derivatives outside a living body, which is a challenge in their cultivation. Unlike many traditional processes that use a cell's capabilities to produce a protein, use of stem cells aims to generate the cells themselves as the product. Some of the 30 applications will benefit from the direct expansion of stem cells (for example, hematopoietic stem cell transplantation) ${ }^{2}$, whereas others will require the production of a specific differentiated cell type with defined characteristics. This can be done either by controlling the differentiation in a very specific path or by 35 elimination of undesirable cell types that could arise during the production (differentiation) process. The present day exponentially growing effort of stem cell research is having a major need for convergence of more efficient and appropriate laboratory technologies to sustain the growth. One such 40 technology is the bioreactor system, which can be defined as an industrial form of contained reaction vessel with well-defined, controlled conditions for specific culture outcomes ${ }^{3}$. Compared with static culture condition, the use of bioreactors can overcome some limitations of static culture, including the lack of mixing 45 and the need for frequent medium replacement rates ${ }^{4}$.
Forinstance, a recent study has shown that induced pluripotent stem cells can be generated more efficiently in stirred culture compared to static culture ${ }^{5}$. However, the success of maximum expansion of stem cells is dependent not only on the bioreactor ${ }_{50}$ design but also on several other parameters.It is well known that stem cells can start to differentiate into mature tissue cells and lose their pluripotency when they are exposed to the intrinsic properties of their extracellular matrix (ECM). ECM stimuli, including matrix structure, chemistry, substrate elasticity, and ${ }_{55}$ presence of growth factors, can elicit stem cell differentiation ${ }^{6-7}$. The manipulation of the intrinsic parameters may render these cells unsuitable for various uses, and hence optimization of the extrinsic parameters is a more suitable method for the purpose of getting maximum expansion of stem cells in a bioreactor.

60 Microfluidic devices expand our ability to control material transport, and material manipulation, at micro-scale. Microfluidic systems are particularly advantageous for biological and medical applications; these advantages include the ability to create biomimetic structures that mimic the in vivo cellular ${ }_{65}$ microenvironment $^{8}$, allow experimental parallelization in wellcontrolled conditions, reduce reagent consumption, and require shorter sample analysis time ${ }^{9}$. Micro-bioreactors are miniaturized versions of conventional bioreactors, where high-throughput cell based assays can be carried out at low cost compared with their 70 macro-scale counter-parts. For development of a micro-bioreactor for stem cell expansion, the micro-bioreactor should mimic the in vivo microenvironment of stem cells in order to retain the selfreplicating ability and pluripotency of stem cells. The construction materials for the micro-bioreactor should be 75 carefully chosen avoiding stimuli such as growth factors, but yet 
they should be biocompatible and should be surface functionalized to provide cell adhesion sites, since pluripotent stem cells are anchorage dependent ${ }^{1}$.

Polydimethylsiloxane (PDMS) is a popular material which has 5 been widely used for microfluidic device construction, especially for biological applications due to its attractive properties, including elastomeric properties that are similar to soft biological tissues, biocompatibility, optical transparency, high gas permeability, ease of fabrication (simple fabrication by replica 10 molding), and cost effectiveness ${ }^{10-12}$. Despite the advantages of PDMS, the major drawback of using untreated PDMS is its low cell adhesiveness, high hydrophobicity, which restricts fluid flow in microchannels, and surface fouling problems, resulting in substantial sample loss and low device performance.

15 The properties of micro-bioreactor surfaces have a strong influence on cell analysis. A micro-bioreactor surface should be able to support cell growth, and should be protein resistant in order to prevent undesired adsorption of analyte molecules such as protein and DNA. Native PDMS surface is not suitable for

20 stem cell cultivation; when using a PDMS based microbioreactor, the PDMS surface should be functionalized to prevent protein adsorption, to avoid contamination and to minimize loss of precious samples that are of micro/nano volume ${ }^{13}$. PDMS surfaces can be functionalized by plasma treatment to create 25 silanol groups. The activated surface is then functionalized with amine groups as anchors for further grafting with a hydrophilic polymer to prevent protein adsorption. (3Aminopropyl)triethoxysilane (APTES) and (3aminopropyl)trimethoxysilane (APTMS) are organosilanes that 30 are commonly used to introduce amine groups for further protein or biomolecule immobilization on microfluidic devices ${ }^{14}$.

This study presents a novel and inexpensive method to prepare a disposable micro-bioreactor for stem cell expansion. The microbioreactor was constructed using PDMS in the form of a fixed 35 bed reactor with a microchannel serving as the reactor bed. A method to functionalize the micro-bioreactor to facilitate stem cell adhesion and propagation was developed. Herein, trimethoxysilylpropyl (polyethyleneimine) was investigated as an alternative organosilane for micro-bioreactor surface aminization. 40 Trimethoxysilylpropyl (polyethyleneimine) has been shown to aminize PDMS surfaces more efficiently compared with APTMS and N-(3-trimethoxysilylpropyl) diethylenetriamine ${ }^{15}$, due to the presence of multiple amines per molecule. Carboxymethyl cellulose (CMC) is a derivative of cellulose that is commonly 45 used as a Food and Drug Administration (FDA)-approved disintegrate in pharmaceutical manufacturing ${ }^{16}$. It is watersoluble, biocompatible and available abundantly at low cost, making it an attractive biomaterials candidate. CMC has been employed as wound dressing materials and co-excipients with 50 drugs $^{17}$. CMC has been demonstrated to inhibit postsurgical and postoperative adhesions ${ }^{18-20}$. This study investigated the potential of using CMC as a low-cost non-fouling material. The aminized PDMS microchannel was further functionalized with $\mathrm{CMC}$, and the resulting protein resistance was examined.

55 Most mammalian cells are anchorage dependent. Cell adhesion is essential to organogenesis, wound healing, tissue homeostasis and remodelling. Cell attachment to a proper anchoring surface also plays an important role in regulating cell survival, cell cycle progression, and tissue-specific phenotype expression. Abnormal 60 adhesion processes can lead to many pathological conditions such as tumour metastatic invasion and blood clotting defects ${ }^{21}$. PDMS and CMC possess many favourable properties that make it attractive as a material for microfluidic device fabrication, but they both lack ligands that mediate cell adhesion.

${ }_{65}$ Gelatin derived from collagen has widely been used for pharmaceutical and medical applications due to its abundant availability, cost-effectiveness, excellent biodegradability and biocompatibility, and non-immunogenic properties (Young et al., 2005). It is known that gelatin contains Arginine-glycine70 aspartate (RGD) motifs, RGD peptides provide a high-affinity site for cell binding, and are often incorporated in biomaterials to promote cell adhesion ${ }^{22-23}$ Therefore, the CMC functionalized microchannel was further functionalized with gelatin, which contains RGD peptide to promote cell-substrate adhesion. The 75 performance of the bio-functionalized micro-bioreactor was evaluated for its performance in facilitating cell expansion. The ability of the bio-functionalized surface to maintain stem cell pluripotency was also evaluated.

\section{Experimental}

\section{${ }_{80}$ Materials}

PDMS substrates were prepared using a silicon elastomer kit (Sylgard 184, Dow Corning, MI) and mixed at a 1:10 curing agent to base ratio. Trimethoxysilylpropyl(polyethyleneimine) (50\% in isopropanol) $\left(\mathrm{M}_{\mathrm{w}}=2000-4000\right)$, was purchased from ${ }_{85}$ GelestInc, USA. N-hydroxysuccinimide (NHS), 1-ethyl- 3-(3dimethylaminopropyl)carbodiimidehydrochloride (EDC), carboxymethyl cellulose sodium salt $\left(\mathrm{CMC}, \mathrm{M}_{\mathrm{w}} \sim 90 \mathrm{kDa}\right)$, albumin-fluorescein isothiocyanate conjugate (BSA-FITC), bovine serum albumin (BSA), acid orange II, and 2-(N90 morpholiino)ethane sulfonic acid (MES) were purchased from Sigma-Aldrich, Australia. Calcein AM, 4',6-diamidino-2phenylindole, dilactate (DAPI), Texas Red ${ }^{-X}$ phalloidin, Dulbecco's modified Eagle's medium (DMEM), non-essential amino acids, GlutaMAX ${ }^{\mathrm{TM}}$, penicillin-streptomycin were 95 obtained from Life Technologies, Australia. N-hexane was obtained from Merck. Gelatin $\left(\mathrm{M}_{\mathrm{w}}=80-140 \mathrm{kDa}\right)$ was obtained from Wako. Unless stated otherwise, all other chemicals are purchased from Sigma-Aldrich, Australia.

\section{Fabrication of PDMS Microchannels}

The PDMS microchannel was fabricated using the photolithographic fabrication method. A dark field photomask with microchannel pattern of $200 \mu \mathrm{m}$ width, $50 \mu \mathrm{m}$ height and 3 $\mathrm{cm}$ length was designed using AutoCAD. Standard 105 photolithography was employed to fabricate the Si master mold for PDMS replication. In brief, SU8-2050 (Microchem) was spin coated on wafer at 500 and $1500 \mathrm{rpm}$ for $5 \mathrm{~s}$ and $30 \mathrm{~s}$, respectively. The spun coated wafer was placed on a hotplate at $65^{\circ} \mathrm{C}$ and $95^{\circ} \mathrm{C}$ in sequence for $5 \mathrm{~min}$ and $20 \mathrm{~min}$, respectively. The wafer was 10 then allowed to cool to RT. The photomask was lowered over the photoresist coated wafer to form a sandwich assembly, and was irradiated under UV at $240 \mathrm{~mJ} / \mathrm{cm}^{2}$ in a Contact Aligner (Mask Aligner, EVG 620). After UV-irradiation, the wafer was baked at $65{ }^{\circ} \mathrm{C}$ for $5 \mathrm{~min}$ followed by $95{ }^{\circ} \mathrm{C}$ for $10 \mathrm{~min}$ and then cooled 
down to RT. The wafer was subsequently developed for $15 \mathrm{~min}$ followed by rinsing in acetone and isopropyl alcohol (IPA) before drying with dry nitrogen. The patterned master mold was placed in a petri dish.

5 The PDMS prepolymer was cast onto the silica master mold. After curing at $85^{\circ} \mathrm{C}$ for $4 \mathrm{~h}$, the PDMS microchannel replica was gently peeled off from the master mold and cut into a rectangular plate of dimension $2 \times 3 \mathrm{~cm}^{2}$ to prepare micro-bioreactor assemblies. Holes for inlet and outlet ports at both ends of 10 microchannel were punched with a syringe needle. The PDMS substrates were then washed with hexane for 2 days to remove uncured prepolymer, followed by isopropanol to remove contaminants.

\section{Aminization of PDMS Substrates (PDMS-NH $\mathbf{N H}_{2}$}

The PDMS substrate containing the microchannel pattern was activated by oxygen plasma treatment at $1000 \mathrm{mTorr}$ for $60 \mathrm{~s}$ in a plasma cleaner (Harrick Plasma, PDC-001/002, USA) to generate silanol groups, and then bound to a microscope slide immediately 20 to allow irreversible sealing (Fig. 1). The microchannel was filled with $4 \%(\mathrm{v} / \mathrm{v})$ trimethoxysilylpropyl(polyethyleneimine) in acetone in a single injection using a syringe, and allowed to reactfor $2 \mathrm{~h}$ at RT. The modified microchannel was rinsed with ethanol and deionized (DI) water to remove any unbound 25 polymer, and dried at $65^{\circ} \mathrm{C}$ for $3 \mathrm{~h}$. The microchannel was then equilibrated with MES buffer (50 mM, pH 5.0) for next step modification. The aminized PDMS substrate is denoted as PDMS-NH $\mathrm{N}_{2}$.

\section{Determination of Amine Content}

Amount of surface accessible amine was quantified using an Acid Orange II assay ${ }^{24}$. In brief, PDMS films were cut into $2 \mathrm{~cm}$ $\times 2 \mathrm{~cm}$ samples and aminizedaccording to the above aminization protocol; samples were incubated in $1 \mathrm{ml}$ of Acid Orange II 35 solution in DI water $(500 \mu \mathrm{M}, \mathrm{pH} 3)$ overnight at RT. Unbound Acid Orange II was removed by washing the samples with copious water at $\mathrm{pH} 3$ (adjusted by $\mathrm{HCl}$ ). The samples were then incubated in $1 \mathrm{ml}$ of DI water at $\mathrm{pH} 12$ (adjusted with $\mathrm{NaOH}$ ) overnight to allow the bound dye to detach. The amount of the 40 bound dye was quantified by measuring the optical density at 492 nm. Unmodified PDMS substrates served as controls. A series of Acid Orange II standard solutions $(100-500 \mu \mathrm{M})$ were prepared in DI water at $\mathrm{pH} 12$ and used to establish the standard curve. The amount of surface amine groups was calculated based on the

45 assumption that each Acid Orange II molecule complexes with one molecule of the amine.

\section{Surface grafting of CMC onto PDMS- $\mathrm{NH}_{2}$ substrates (PDMS- NH-CMC)}

50 EDC and NHS (1:1) were added to $0.6 \mathrm{mg} / \mathrm{ml} \mathrm{CMC} \mathrm{in} \mathrm{MES}$ buffer $(50 \mathrm{mM}, \mathrm{pH} 5.0)$ to obtain a final concentration of 2.0 $\mathrm{mg} / \mathrm{ml}$, and allowed to react for $30 \mathrm{~min}$ at RT. The activated $\mathrm{CMC}$ solution prepared according to the above procedures was injected into the PDMS- $\mathrm{NH}_{2}$ microchannel until the microchannel

55 was fully filled, and was allowed to react at RT overnight. The microchannels were then rinsed by injecting MilliQ water to remove residual reagents followed by injecting 0.1 MES buffer. The samples were dried in an oven at $65^{\circ} \mathrm{C}$ for $3 \mathrm{~h}$. The $\mathrm{CMC}$ grafted substrate is denoted as PDMS-NH-CMC.

60

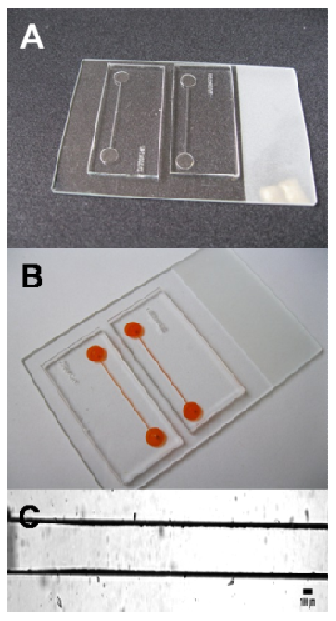

Fig. 1 Photo of (A) PDMS micro-bioreactor, (B) food-dye filled microbioreactor device showing inlets, outlets and microchannels, (C) enlarged bright field view of microchannel, photo taken under a optical microscope (scale bar $=100 \mu \mathrm{m})$.

\section{Surface grafting of gelatin onto PDMS-NH-CMC substrates (PDMS-NH-CMC-GEL)}

Conjugation of gelatin on PDMS-NH-CMC was performed 65 under aseptic condition. PDMS-NH-CMC microchannels were first sterilized in $70 \%$ ethanol overnight. One $\mathrm{ml}$ of EDC $(2.0$ $\mathrm{mg} / \mathrm{ml}$ ) and NHS $(2.0 \mathrm{mg} / \mathrm{ml})$ in MES buffer ( $\mathrm{pH} \mathrm{5})$ was filter sterilized before injecting into a PDMS-NH-CMC microchannel in a single-injection until the microchannel was fully filled. After 70 reacting for $30 \mathrm{~min}$ at $\mathrm{RT}$, sterile gelatin solution $(300 \mu \mathrm{g} / \mathrm{ml})$ in phosphate buffered saline (PBS) was injected into the activated microchannel as a single-injection until the microchannel was fully filled, and allowed to react overnight at RT. The microchannel was then rinsed by injecting sterile MilliQ water 75 followed by PBS. The gelatin-grafted substrate is denoted as PDMS-NH-CMC-GEL.

\section{Surface Characterization of Functionalized PDMS Substrates}

To characterize the functionalized surfaces, PDMS films were 80 cut in $2 \mathrm{~cm} \times 2 \mathrm{~cm}$ samples and functionalized according to the aminization and surface grafting procedures described above. The surface composition analysis of functionalized PDMS was carried out using Fourier Transform Infrared Spectroscopy (FTIR spectrometer, Spectrum 100 series, PerkinElmer, USA). Static 85 water contact angle (WCA) of functionalized PDMS substrates were performed using a sessile drop method ( $2 \mu$ l, MilliQ water) with an optical contact angle measuring instrument (OCA20, Dataphysics Instruments $\mathrm{GmbH}$, Germany). The measurements were performed on at least three different areas on each substrate 90 and the values were averaged. To assess the stability of surface functionalization, the WCAs of PDMS- $\mathrm{NH}_{2}$ and PDMS-NH$\mathrm{CMC}$ were monitored over a period of 25 days. 


\section{Protein Adsorption}

Protein adsorption of functionalized substrates was investigated using a method modified from Goda et $\mathrm{al}^{25}$. In brief, after being equilibrated in PBS at RT overnight, samples with the defined 5 size $\left(4.0 \mathrm{~cm}^{2}\right)$ were immersed in a freshly prepared BSA solution ( $3 \mathrm{mg} / \mathrm{ml}, 1 \mathrm{ml}$ per sample). Adsorptions were allowed to proceed at RT overnight under gentle shaking. The samples were then rinsed with PBS and treated with $1 \%$ SDS (1 ml per sample) for $20 \mathrm{~min}$ to remove the adsorbed protein. The amount of adsorbed 10 protein was quantified using a Micro BCA protein assay kit (Thermo Scientific, Australia). In a separate study, protein adsorption on PDMS and PDMS-NH-CMC was visualized by treating the surface with BSA-FITC using a method modified

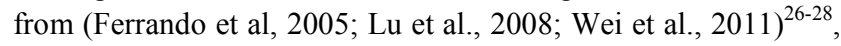
15 and the images were acquired using a laser scanning confocal microscope (Nikon A1Rsi MP) with excitation wavelength at 488 $\mathrm{nm}$ and emission wavelength at $550 \mathrm{~nm}$. The comparison images were obtained using the same confocal microscopy setting.

\section{${ }_{20}$ Cell Culture}

MDA-MB-231 (Human mammary gland adenocarcinoma) and Oct4b2 (murine-derived embryonic stem cell) cell linesobtained from the Monash Institute of Medical Research (Clayton, VIC, Australia) were employed to investigate cell adhesion and 25 proliferation onto the modified PDMS substrates. MDA-MB-231 cells were maintained in high glucose DMEM (11965, Gibco $\left.{ }^{\circledR}\right)$ supplemented with $10 \%$ fetal bovine serum(FBS), and $1 \%$ penicillin-streptomycin at $37^{\circ} \mathrm{C}$ in a humidified $5 \% \mathrm{CO}_{2}$ incubator. Oct $4 \mathrm{~b} 2$ cells were maintained in high glucose DMEM 30 (11995, Gibco $\left.{ }^{\circledR}\right)$ supplemented with 10\% FBS(JRH Biosciences, Australia), $1 \%$ non-essential amino acids, 1\% GlutaMAX ${ }^{\mathrm{TM}}$, $0.5 \%$ penicillin-streptomycin, $0.1 \mathrm{mM} \beta$-mercaptoethanol, and $1,000 \mathrm{U} / \mathrm{ml}$ ESGRO Leukemia inhibitory factor (LIF, Chemicon, Australia). Prior to cell seeding, all substrates were sterilized in ${ }_{35} 70 \%$ ethanol overnight followed by rinsing with sterile PBS. MDA-MB-231 and Oct4b2 cells were seeded separately onto PDMS or functionalized PDMS substrate at densities of $80 \times 10^{3}$ and $40 \times 10^{3} \mathrm{cell} / \mathrm{cm}^{2}$, respectively. Pluripotency of Octb2 cells were monitored by examining their GFP expression using X71 ${ }_{40}$ Olympus fluorescence microscopes. The cell adhesion and cell growth were examined using optical microscopy and laser scanning confocal microscopy. Cell counting was performed using a hemocytometer after trypsinization. For visualization, the nucleus of cells was stained with DAPI, while the filamentous ${ }_{45}$ actin(F-actin) of cells was stained with Texas Red $®$-X phalloidin. In brief, samples were fixed with $4 \%$ formaldehyde for $20 \mathrm{~min}$ at RT and washed 3 times with $1 \times$ PBS buffer, and then permeabilized with $0.1 \%$ Triton X-100-PBS for $2 \mathrm{~min}$, andwashed with PBS. The samples were further incubated with 50 $1 \%$ bovine serum albumin in PBS (BSA-PBS) for $15 \mathrm{~min}$, followed by Texas Red $\AA$-X phalloidin (1/1000 in 1\%BSA-PBS) staining for 1 hour. DAPI was then added to the samples and incubated for $5 \mathrm{~min}$. Cell counting wasalso performed to quantify cell adhesion and cell proliferation.

55

\section{Statistical analysis}

All experiments were performed in at least 3 replicates. The results are presented as average values \pm standard deviation. Multiple groups of data were statistically analyzed using 60 ANOVA analysis of variance; two groups of data were statistically analyzed using the unpaired Student's t-test, $\mathrm{p}$ values lower than 0.05 were considered statistically significant.

\section{Results and Discussion}

\section{Surface functionalization}

65 Fig. 2 illustrated the scheme used for microchannel functionalization. Prior to surface functionalization, the PDMS substrates was washed by hexane to remove uncured monomer, as the migration of low molecular weight species from the bulk to the surface is known as one of the major cause of hydrophobicity 70 recovery of $\mathrm{PDMS}^{29}$. Oxygen plasma was employed to treat PDMS substrate, as plasma treatment has been shown to preferentially remove organic contaminates as well as generating silanol (Si-OH) groups on PDMS ${ }^{30}$. The presence of hydrophilic silanol groups allows microchip sealing and further aminization.

75 It is well known that the effect of plasma treatment is transient as hydrophobic recovery occurs ${ }^{30-31}$. Therefore immediately after plasma treatment, the PDMS substrate was bonded to a microchip to form an irreversible seal,trimethoxysilylpropyl (polyethyleneimine) was then quickly injected into the 80 microchannel to introduce amine groups on the inner surface of the microchannelto form PDMS-NH${ }_{2}$.

$\mathrm{CMC}$ was conjugated onto the $\mathrm{PDMS}-\mathrm{NH}_{2}$ surface via EDC/NHS coupling to form a hydrophilic layer preventing nonspecific protein adsorption. CMC grafting introduces carboxyl 85 groups on the surface of PDMS- $\mathrm{NH}_{2}$ to form PDMS-NH-CMC and enables further modification with desired biomolecules. An EDC-based coupling technique was employed as the EDC reagent does not remain as part of the linkage, which eliminates the possibility of releasing cytotoxic agents when the polymer 90 degrades. In addition the by-product produced by the coupling reaction is water-soluble and can be easily removed ${ }^{32}$. Gelatin, as a model biomolecule, was grafted onto PDMS-NH-CMC to form PDMS-NH-CMC-GEL via EDC/NHS coupling to promote cellsubstrate interactions.

\section{${ }_{95}$ Physiochemical properties of functionalized PDMS}

Acid Orange II assay was performed to confirm and quantify the amount of amine groups introduced on the PDMS substrate. Fig. 3 shows that the amount of amine presence on PDMS- $\mathrm{NH}_{2}$ is significantly higher than that on non-treated PDMS substrate, 100 indicating that the aminization process was successful.

Fig. 4 reveals the FTIR spectra for PDMS (curve A), PDMS$\mathrm{NH}_{2}$ (curve B), PDMS-NH-CMC (curve C), and PDMS-NHCMC-GEL (curve D) substrates, respectively. It has been shown that polyethyleneimine alone has characteristic peaks at 1630 and $1051565 \mathrm{~cm}^{-133}$. The PDMS-NH ${ }_{2}$ spectrum (curve B) showed new bands at $1520-1720 \mathrm{~cm}^{-1}$ and $3360 \mathrm{~cm}^{-1}$, arising from the $\mathrm{NH}$ deformation and $\mathrm{NH}$ stretching of the amine groups, respectively. The peak at $\sim 1600 \mathrm{~cm}^{-1}$ on the PDMS-NH-CMC spectrum (curve C) is attributed to the carboxylic acid groups, which confirmed 110 the successful grafting of CMC on PDMS- $\mathrm{NH}_{2}$.

Verification of the existence of successive functionalization of PDMS was obtained through WCA measurements as the 
functionalization was conducted. Fig. 5A shows the change in wettability of PDMS after each step functionalization. The WCA of native PDMS was found to be $116 \pm 0.3^{\circ}$, which is consistent with the inherent hydrophobicity of PDMS. After the PDMS was 5 aminized, the WCA of resulting PDMS- $\mathrm{NH}_{2}$ was found to be $55^{\circ}$, and the WCA decreased to $22^{\circ}$ after further functionalization with $\mathrm{CMC}$, indicating that the hydrophobic PDMS surface has converted to a hydrophilic surface. The enhanced hydrophilicityis attributed to the surface hydroxyl and carboxylic acid groups on ${ }_{10}$ PDMS-NH-CMC. Further gelatin conjugation slightly increases the WCA from $22^{\circ}$ to $31^{\circ}$, due to the presence of hydrophobic amino acid components on the modified surface. Nevertheless, the final characteristic of functionalized PDMS is still much more hydrophilic than native PDMS

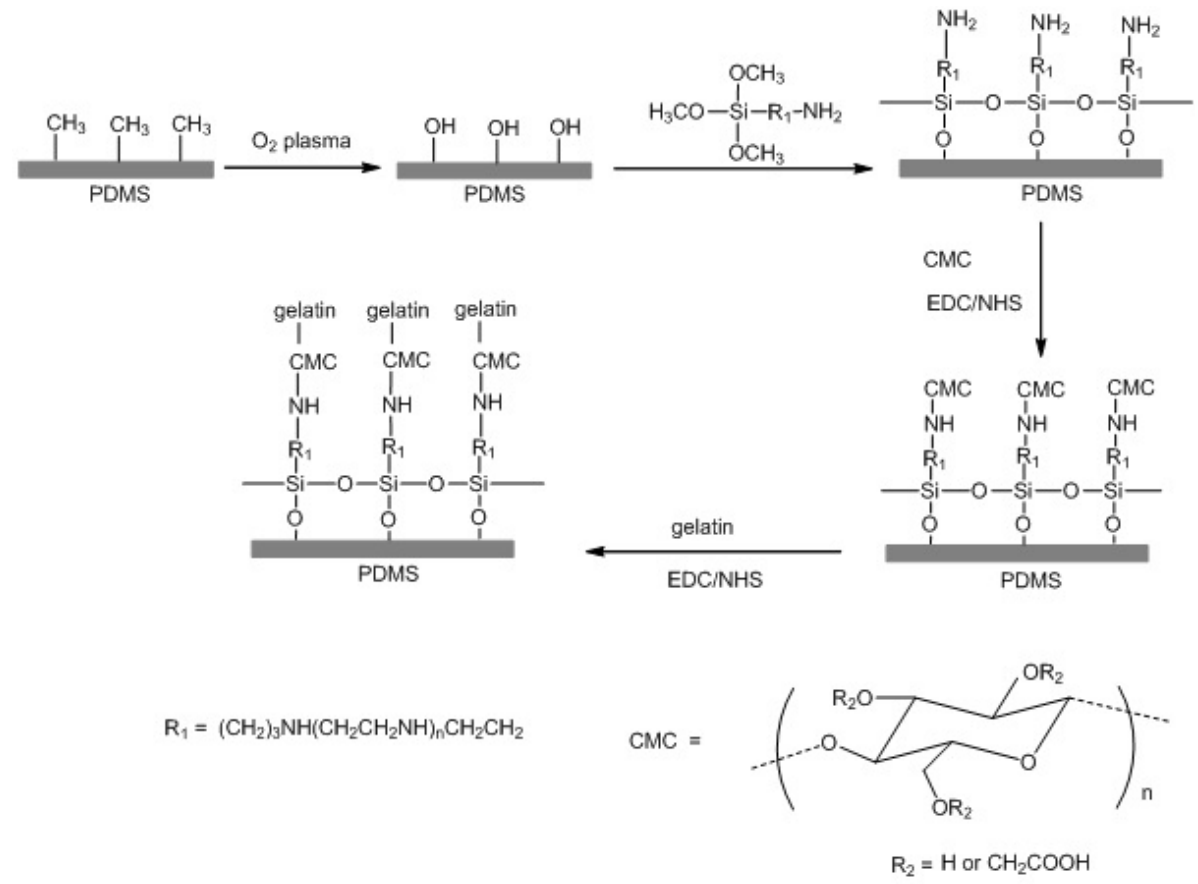

Fig. 2Schematic illustration of the surface functionalization procedure.

The WCAs of PDMS-NH $\mathrm{NH}_{2}$ and PDMS-NH-CMC were monitored for another 25 days to assess the stability of the surface functionalization. As shown in Fig. 5B, both $\mathrm{PDMS}^{-\mathrm{NH}_{2}}$ and PDMS-NH-CMC substrate remained hydrophilic over a 20 period of 16 days. After that time, the WCA of $\mathrm{PDMS}-\mathrm{NH}_{2}$ and PDMS-NH-CMC become stabilized at around $67^{\circ}$ and $77^{\circ}$, respectively.Although partial recovery of hydrophobicity was observed after 16 days, both PDMS- $\mathrm{NH}_{2}$ and PDMS-NH-CMC substrates remain more hydrophilic compared to native PDMS ${ }_{25}$ that displayed a WCA of $116^{\circ}$ (Fig 5A). It was observed that the WCA of PDMS-NH-CMC was lower than that of PDMS-NH $\mathrm{N}_{2}$ at each time point, indicating that the grafting of $\mathrm{CMC}$ onto the PDMS- $\mathrm{NH}_{2}$ surface further reduces the hydrophobicity.

It is known that hydrophobicity recovery of PDMS is not solely 30 due to migration of low molecular weight species, but also due to physical surface recovery of PDMS, i.e., reorientation of $\mathrm{PDMS}^{34}$. The high molecular weight CMC forms a dense hydrophilic coating on PDMS surface; this coating minimizes the underlying PDMS from air exposure and subsequent PDMS re35 orientation, thereby improving surface hydrophilicity retention. The use of a high molecular weight organosilane, trimethoxysilylpropyl(polyethylene imine), may also contribute to formation of a dense coating that prevents PDMS surface recovery. In addition, the hydrophobicity recovery of PDMS can 40 also be affected by storage conditions; for example, it is known that storing the samples in a wet environment such as in water and Luria-Bertani broth, can retain surface hydrophilicity of $\mathrm{PDMS}^{35}$. The storage condition can be optimized in a future study to maximize the long-term stability of PDMS-NH-CMC 45 hydrophilicity.

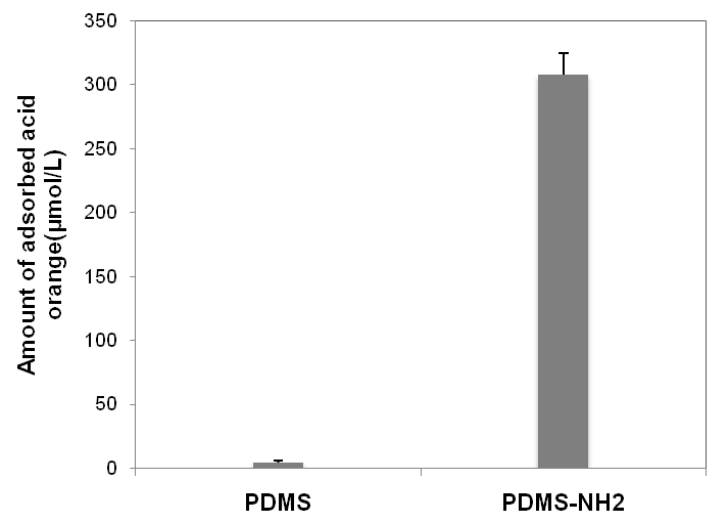

Fig. 3 Quantification of surface amine on native PDMS and PDMS-NH by measuring the amount of adsorbed acid orange. 


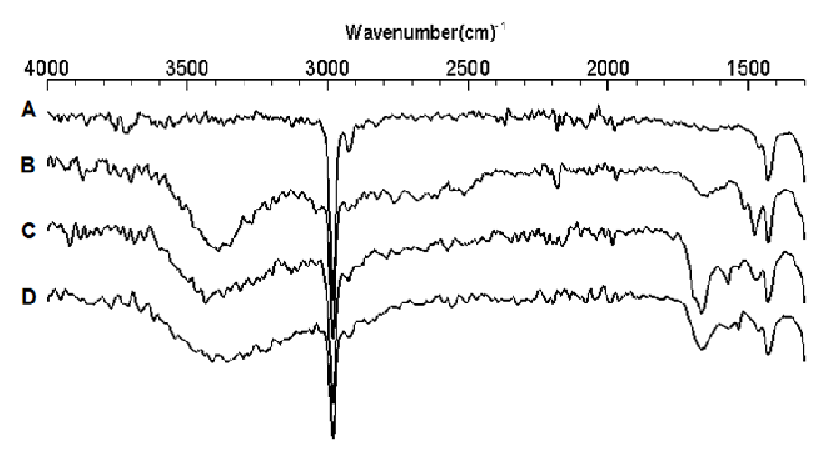

Fig. 4 FTIR spectra of (a) PDMS, (b) PDMS-NH $\mathrm{N}_{2}$, (c) PDMS-NH-CMC, and (d) PDMS-NH-CMC-GEL.
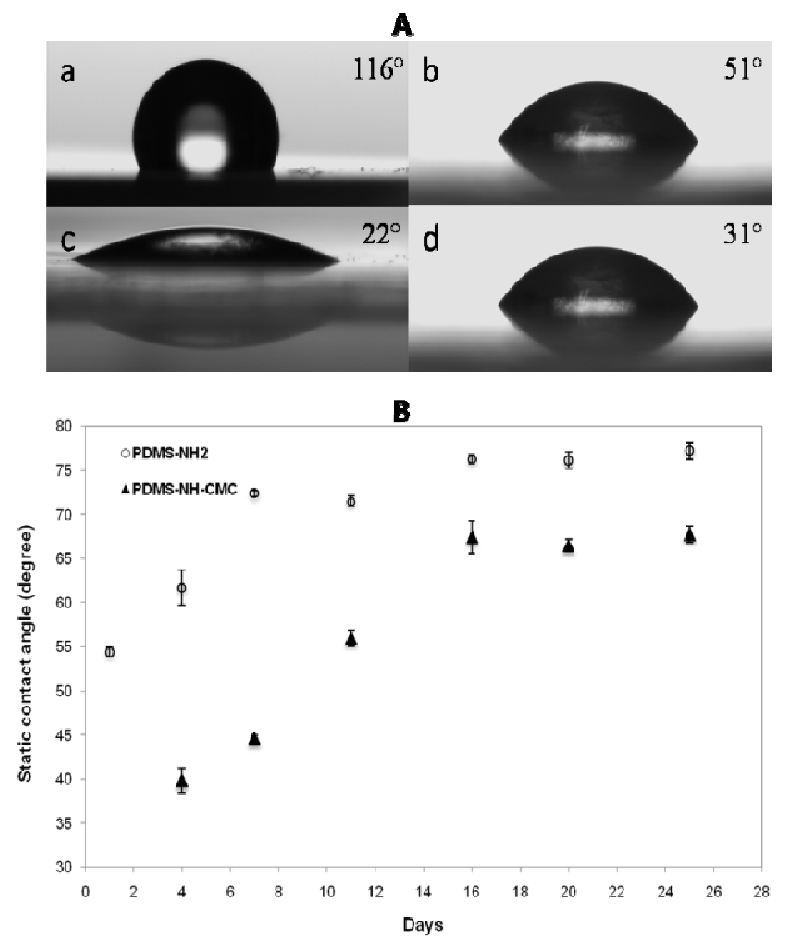

Fig. 5 (A)Static water contact angle of (a) PDMS, (b) $\mathrm{PDMS}^{-\mathrm{NH}_{2}}$, (c) PDMS-NH-CMC, and (d) PDMS-NH-CMC-GEL substrates measured at day 1. (B) shows the variation of static contact angles of $\mathrm{PDMS}^{-\mathrm{NH}_{2}}$ and PDMS-NH- CMC as a function of the storage time in air.

\section{Protein adsorption}

BSA is a protein produced by the liver and functions as a transport protein in vivo. BSA is the most abundant protein component of bovine plasma ${ }^{36}$. BSA-FITC was selected as a model biofouling protein for study of protein adsorption on the CMC functionalized substrate, because BSA is inexpensive, well characterized and commonly employed in protein adsorption studies $^{37-39}$. Native PDMS substrate served as the control. As shown in Fig 6A, BSA-FITC was readily adsorbed by the native PDMS substrate. In contrast, only very weak fluorescent signals were observed for the PDMS-NH-CMC substrate, indicating that the $\mathrm{CMC}$ functionalization was effective in preventing
BSAadsorption.

The amount of BSA adsorption on PDMS, PDMS-NH $\mathrm{N}_{2}$, and PDMS-NH-CMC substrates were quantified using BCA protein assay. Fig $6 \mathrm{~B}$ shows that the amounts of adsorbed BSA decreased significantly in the sequence of PDMS $>$ PDMS- $\mathrm{NH}_{2}>$ PDMSNH-CMC.

Adsorption of BSA on a hydrophobic surface is driven by nonpolar attraction between BSA molecules toward the surface. However, adsorption of BSA on a charged surface is predominantly driven by electrostatic interaction between the charged functional groups on BSA molecules and the oppositely charged surface ${ }^{40}$. It is well known that hydrophobic interaction is the major driving force of protein adsorption, with protein adsorption tending to be greater on a hydrophobic surface compare to a hydrophilic surface ${ }^{41}$. Compared to native PDMS substrate, the amount of protein adsorbed onto PDMS- $\mathrm{NH}_{2}$ and PDMS-NH-CMC substrates decreased by about 1.4 and 2 times, respectively. These results suggested that protein adsorption on PDMS is reduced by rendering its surface hydrophilicity through hydrophilic polysaccharide functionalization. At physiological $\mathrm{pH}$, the carboxylic acid groups of CMC are deprotonated and become anionically charged, which is similar to glycosainoglybcans that play major roles as lubricants in cartilaginous tissues ${ }^{16}$. The high water retention and lubricant nature of $\mathrm{CMC}^{42}$ makes it a favourable anti-fouling coating for PDMS microchannels.

In contrast to carboxylic acid groups, the majority of amine groups of polyethyleneimine are protonated and become cationic charged at physiological $\mathrm{pH}^{43}$. The observations of protein adsorption on surface functionalized with different functional groups from Chapman et al. ${ }^{44}$ suggests that a reduction in the hydrogen bond donor moieties in the functional group results in a reduction in protein adsorption. Tangpasuthadol et al. ${ }^{45}$ studied the adsorption of lysozyme (hydroxyl and amine rich protein) and BSA (carboxylic acid rich protein) on chitosan surface, and found that the adsorption of BSA was lower on carboxylic acid rich chitosan, possibly due to charge repulsion. BSA as a carboxylic acid rich protein was found to adsorb less onto PDMS-NH-CMC substrates compared to PDMS- $\mathrm{NH}_{2}$ substrates, possibly due to charge-charge repulsion. The result obtained in this study appears to fit well with the study of interaction of charged proteins on hydrophobic and charged hydrophilic surface ${ }^{41-44-45}$.

It was observed that the difference in protein adsorption level between PDMS and functionalized PDMS obtained by confocal microscopy method appeared to be greater than that obtained by the BCA protein assay method. The discrepancy may be due to the fact that confocal microscopy method measures the local protein adsorption, whereas the BCA protein assay method measures the protein adsorption of the whole sample. For future studies, it is suggested that such difference can be expected dependent on the chosen measurement method and other factors such as sample homogeneity. 

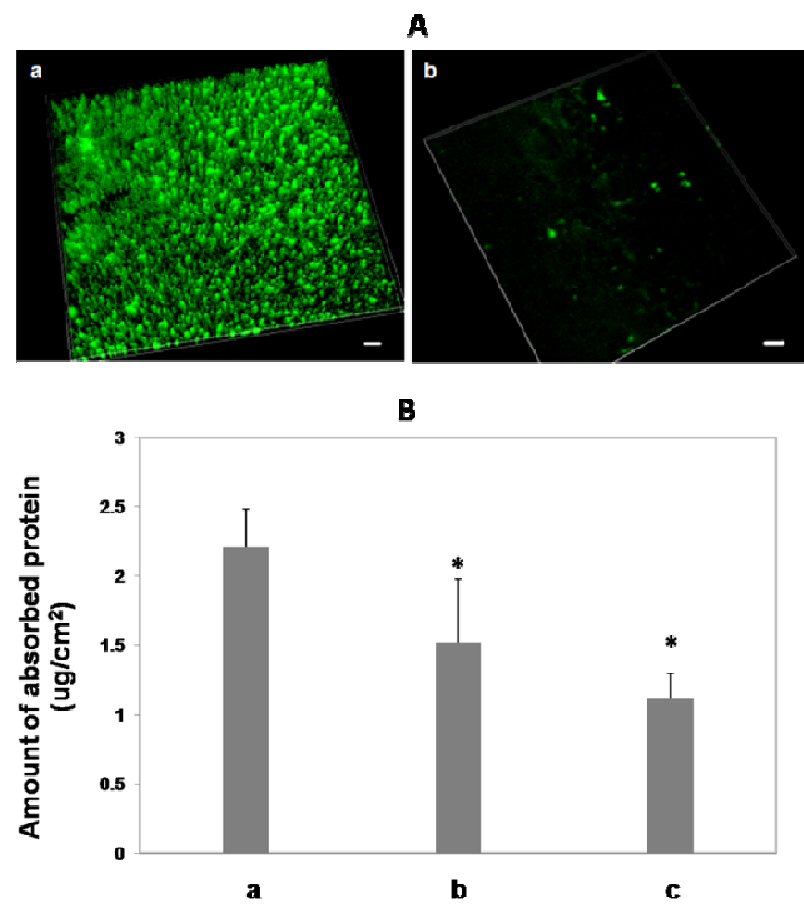

Fig. 6 (A) Confocal microscopy images showing BSA-FITC adsorption on PDMS and PDMS-NH-CMC. (scale bar $=100 \mu \mathrm{m}$ ). (B) shows the influence of surface modification on BSA adsorption on (a) PDMS, (b) PDMS-NH ${ }_{2}$, and (c) PDMS-NH-CMC substrates. Data presented as 5 average values \pm standard deviation $(* \mathrm{p}<0.05)$.

\section{Cell adhesion}

MDA-MB-231 cell adhesion on PDMS-NH-CMC-GEL substrate was examined and compared to that on PDMS. F-actin was detected using Texas Red-X phalloidin. F-actin is shown in 10 red while nuclei are shown in blue. As expected, MDA-MB-231 cells appeared to form aggregates and were not attaching to native PDMS substrate. In contrast, cells adhered well onto PDMS-NH-CMC-GEL and proliferated until they reached confluence. Cell adhered onto PDMS-NH-CMC-GEL displayed 15 more well-spread F-actin and normal cell-ECM adhesion (Fig. 7), revealing that the gelatin functionalization process provides appropriate adhesion sites to the cells, thus allows a normal cytoskeleton formation. For cell growth on PDMS substrate, the organization of F-actin is more irregular. These results reflect the

20 importance of cell-substrate interaction. They also highlight that cell adhesive ligands can be readily incorporated onto a PDMS$\mathrm{NH}-\mathrm{CMC}$ to form PDMS-NH-CMC-GEL based micro-bioreactor while retaining their efficacy for cell adhesion.

\section{Maintenance of pluripotency and proliferation potential of embryonic stem cells}

Oct $4 \mathrm{~b} 2$ cells are undifferentiated murine embryonic stem cells that can be cultured on feeder-freeculture medium in the presence of LIF. Oct $4 \mathrm{~b} 2$ cell adhesion and proliferation on PDMS-NH${ }_{30}$ CMC-GEL substrate was monitored and compared to that on PDMS, PDMS-CMC, and a TC treated cell culture dish. The morphology of Octo4b2 cells cultured on different substrates is shown in Fig. 8. As expected, cells cultured on PMDS substrate were round and small after 1 day, and they appeared to form 35 embryonic body (EB) like structures after 4 days, which were floating in the medium instead of attaching to the PDMS substrate, indicating that PDMS substrate without any functionalization is not suitable for stem cell adhesion. EB formation entails a transition of ESCs to a three-dimensional 40 structure consisting of three embryonic layers: endoderm, mesoderm and ectoderm lineages, similar to embryogenesis ${ }^{46}$. Unlike anchorage dependent stem cells, EB formation takes place on a non-adherent surface. A hydrophobic PDMS surface is known to promote the development of EBs; the results present ${ }_{45}$ here are in consistent with the findings of Valamehr et al. ${ }^{47}$.

Although, some cell adhesion and cell growth were observed on the PDMS-NH-CMC surface, the cells appeared to be small and not well spread after 1 day, and cells tended to form aggregates as they proliferated. The aggregation of cells on ${ }_{50}$ PDMS-NH-CMC led to a decline in the proliferation rate compared to that of PDMS-NH-CMC-GEL culture, indicating that the cells did not adhere well onto the PDMS-NH-CMC substrate due to the lack of cell adhesion ligands. In contrast, cells grown on PDMS-NH-CMC-GEL appeared to be larger with 55 more spatially dispersed bodies. The cell number increased after 4 days similar to those grown on a TC treated cell culture dish. The cell density of PDMS-NH-CMC-GEL was approximately three times higher than that of PDMS-NH-CMC. This indicates that PDMS-NH-CMC-GEL facilitates cell adhesion via the RGD ${ }_{60}$ peptide moiety on gelatin. Oct $4 \mathrm{~b} 2$ cells contain the Oct4-green fluorescence protein (Oct4-GFP) reporter.

Oct4 is a pluripotency- and germ-cell-specific marker, and the expression of Oct4-GFP is correlated with pluripotency. The pluripotency of Oct4b2 was monitored by examining the green ${ }_{65}$ fluorescence protein (GFP) expression of Oct $4 \mathrm{~b} 2$ cells. The maintenance of pluriopotency was illustrated through the fluorescence expressed by Oct4-GFP (depicted in green) in the cytoplasm of Oct4b2 cells observed in the fluorescence microscopy images taken 4 days after cell seeding (Fig. 8). The 70 polysaccharide functionalized PDMS, namely PDMS-NH-CMCGEL, does not appear to cause undesired differentiation of Oct $4 \mathrm{~b} 2$ cells. 

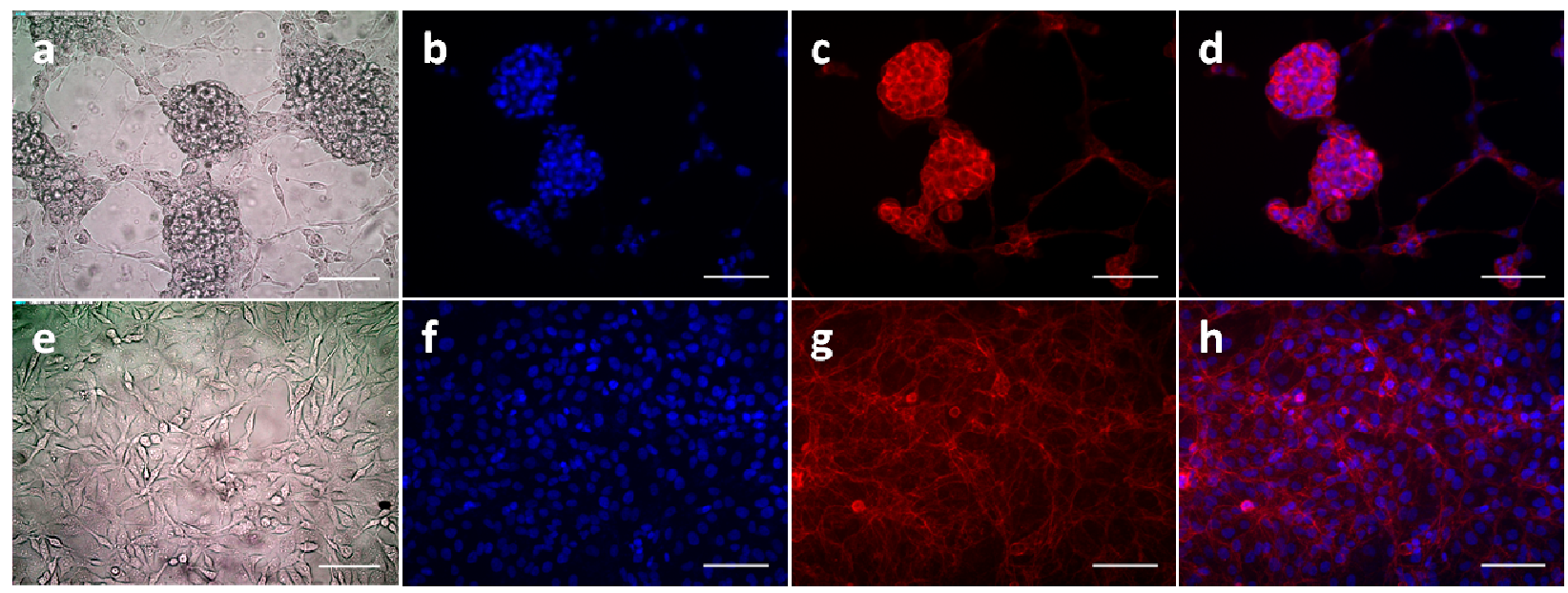

Fig. 7. Brightfield and fluorescence microscopy images of MDA-MB-231 cells cultured on (a,b,c,d) PDMS, and (e,f,g,h) PDMS-NH-CMC-GEL. (a,e) Bright field images. (b, f) fluorescence microscopy images show cell nuclei stained by DAPI (blue), (c, g) F-actin stained by Red®®-X Phalloidin (red), $(\mathrm{d}, \mathrm{h})$ overlay of DAPI and Red $\circledast$-X Phalloidinfluorescence channels. $($ scale bar $=100 \mu \mathrm{m})$.

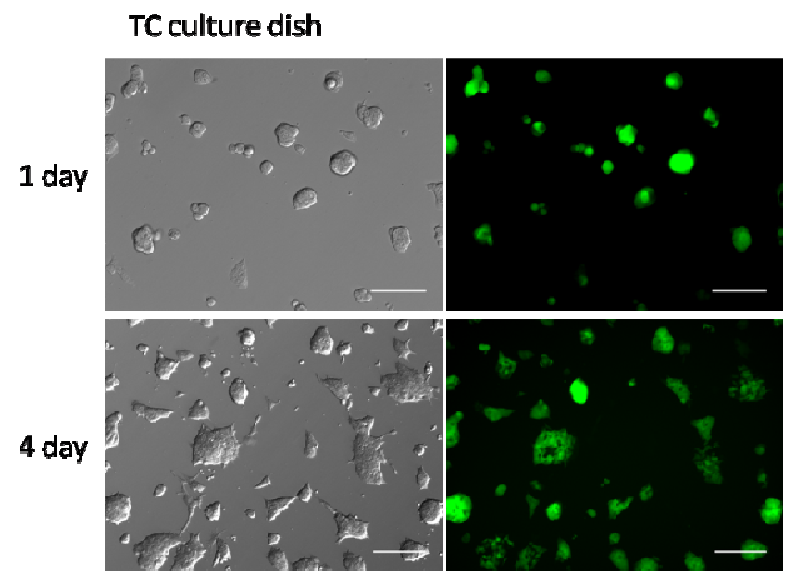

PDMS-NH-CMC

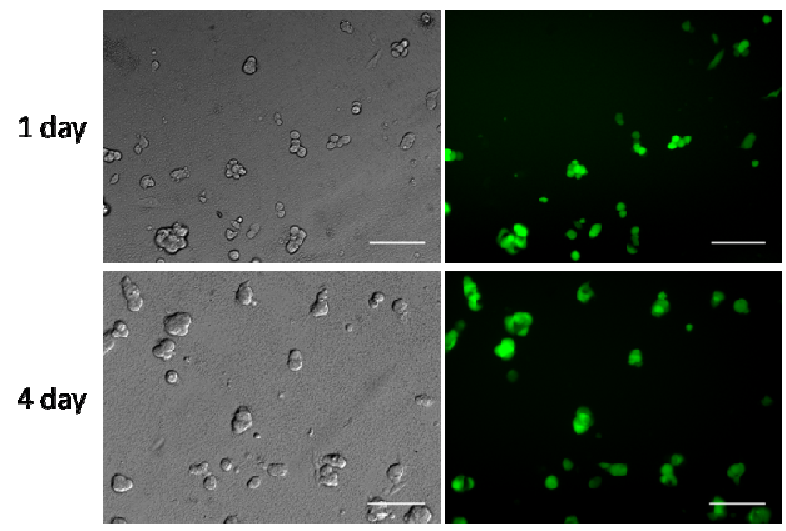

\section{PDMS}

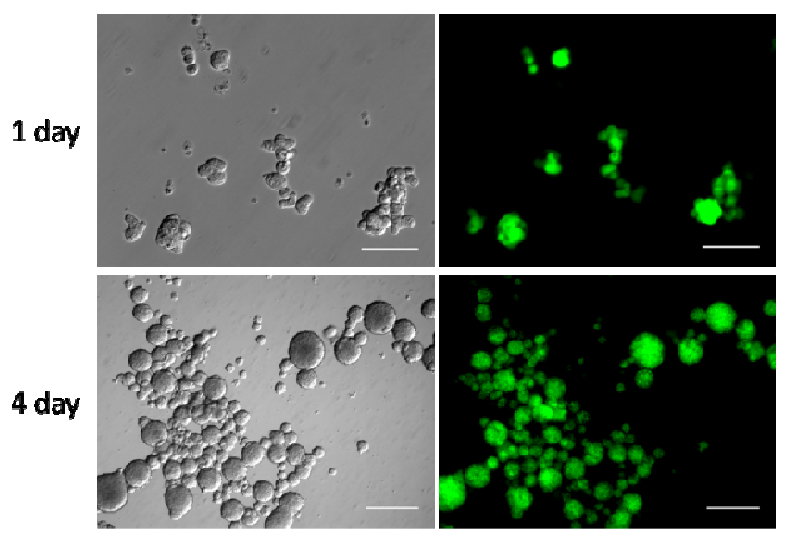

\section{PDMS-NH-CMC-GEL}

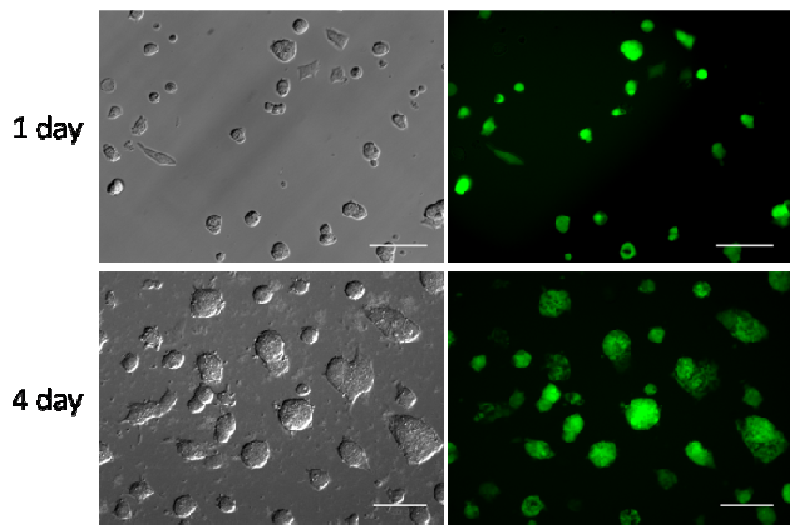

Fig. 8. Phase contrast images of Oct $4 \mathrm{~b} 2$ cells cultured on different substrates. Fluorescence microscopy images show Oct-GFP expression of Oct $4 \mathrm{~b} 2$ cells (scale bar for day one is $100 \mu \mathrm{m}$ and for day 4 is $250 \mu \mathrm{m}$ ).

\section{Cell growth in micro-bioreactors}

Microfluidic systems have the potential to perform multiple biochemical assays in a single microchip9, and provide a feasible alternative to the conventional TC cell culture flask by lowering
5 reagent consumption, improving sensitivity and allowing high throughput operation ${ }^{48}$. To show that PDMS-NH-CMC-GEL microchannels can support cell growth, cells were cultured inside the microchannels and monitored over a period of 4 days. 
MDA-MB-231 cell attachment and cell morphology were inspected using phase contrast microscopy as shown in Fig. 9A. Four hours after cell seeding, MDA-MB-231 cells appeared to adhere onto the PDMS-NH-CMC-GEL microchannel surface. 5 MDA-MB-231 cells appeared to spread out showing an epithelial-like morphology and proliferating after 1 day. Live/dead staining was performed using Calcein AM to confirm the viability of cells inside microchannels after 4 days. Fig. 9A revealed that the majority of cells remained viable (stained in 10 green) inside the microchannel and demonstrated the ability of the present method to support cell cultivation.

The proliferation of cells on different substrates was quantified and the results are summarized in Fig. 9B,C. The cell growth on the PDMS-NH-CMC-GEL substrate was compared to that on the

15 PDMS control substrate over four consecutive days. The results revealed that the number of cell grown on the PDMS-NH-CMCGEL substrate was much higher than those cultured on the PDMS substrate, for instance, the number of MDA-MB-231 and Oct4b2 cells on PDMS-NH-CMC-GEL is approximately 2 times and 2.3

20 times greater than that on PDMS at day three, respectively. The rate of cell proliferation on PDMS-NH-CMC-GEL also appeared to be higher than that on the PDMS substrate. The proliferation of cells implies that the functionalized microchannel surface is biocompatible with cells. It is worthwhile to mention that the 25 functionalized microchannel system derived in this study can be employed as a perfusion micro-bioreactor when integrated with an appropriate flow control system. The effect of shear stress on stem cells growth and differentiation compared with those in static culture are currently under investigation.

\section{${ }_{30}$ Conclusions}

We have developed a novel method to prepare a microbioreactor for stem cell expansion. This method is cost effective, and allows functionalization to be carried out by needle injection of reagents into the micro-bioreactor surface, and is thereby 35 compatible with standard microfabrication processes. Enhanced and extended surface hydrophilicity were permitted by the proposed functionalization method. The cytocompatibility has also been demonstrated by cultivating MDA-MB-231 on a functionalized micro-bioreactor surface. We also demonstrated 40 that the functionalized surface facilitates Oct $4 \mathrm{~b} 2$ cell propagation, as well as retaining the undifferentiated phenotype andpluripotency of the cells. The results demonstrate the potential use of the micro-bioreactor as a stem cell study tool.
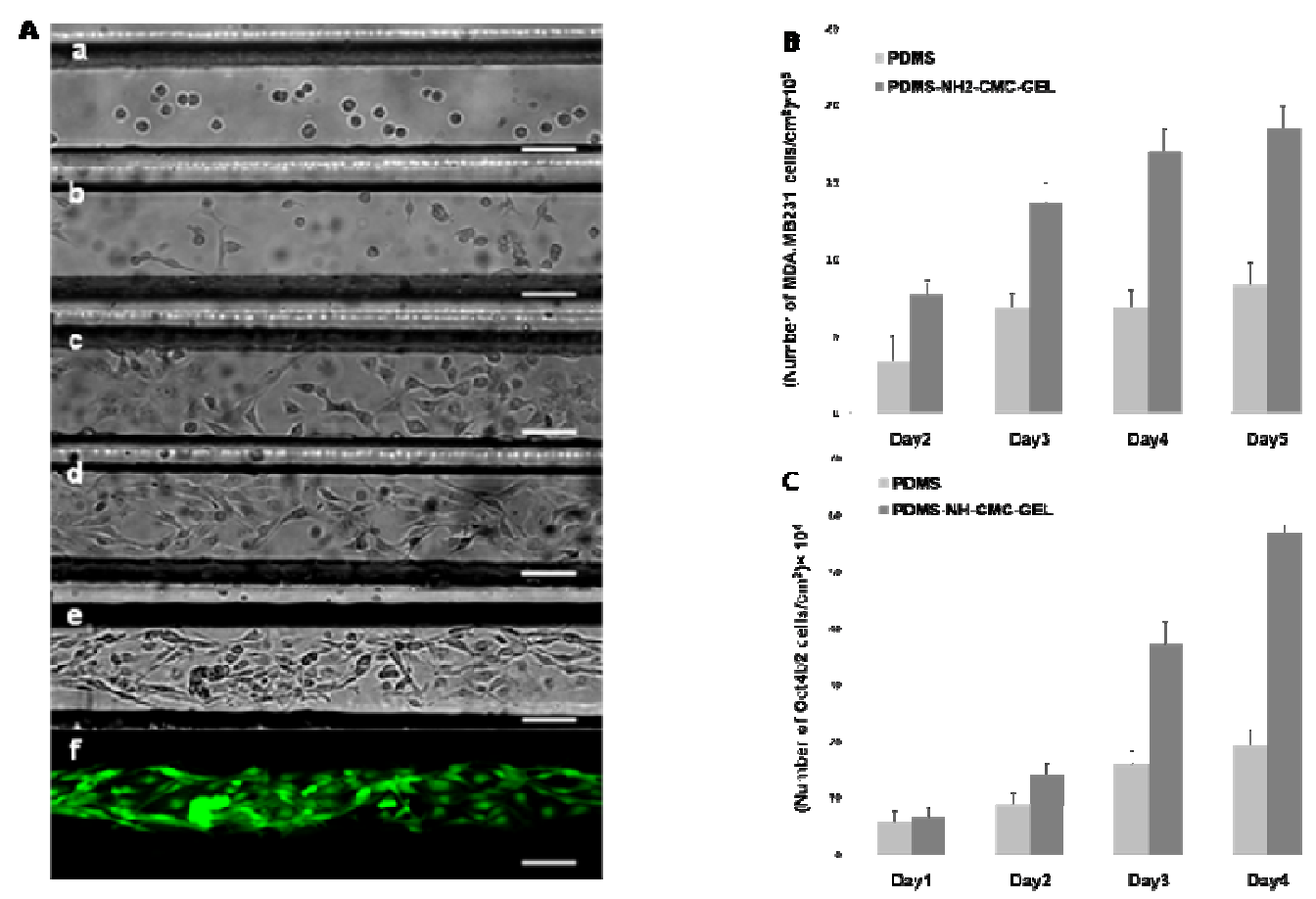

45

Fig. 9 (A) Phase contrast images of MDA-MB-231 cells cultured in PDMS-NH-CMC-GEL functionalized microchannels after (a) $0 \mathrm{hr}$, (b) $4 \mathrm{hr}$, (c) 1 day, (d) 3 days, and (e) 4 days after cell seeding. (f) Fluorescence microscopy image of live cells stained by Calcein AM (green) after 4 days. (scale $\mathrm{bar}=100 \mu \mathrm{m}$ ). (B) shows the proliferation of (a) MDA-MB-231 cells, and (C) Oct4b2 cells on PDMS and PMDS-NH-CMC-GEL substrates was monitored over a period of four days. 


\section{Acknowledgements}

We acknowledge the funding provided by the Department of Mechanical and Aerospace Engineering at Monash University. Funding for this research was also partly provided through an 5 Australia Research Council Discovery Project Grant ARC DP 120102570 and through the Australia-India Strategic Research Fund BF050038.We also thank Dr Paul Verma from Monash Institute of Medical Research (MIMR) for supplying Oct4b2 cells. We would like to thank Dr Ricky Tjeung for his assistance 10 with microchannel fabrication and Ms Karla Contreras for her assistance with cell culturing. This work was performed in part at the Melbourne Centre for Nanofabrication, an initiative partly funded by the Commonwealth of Australia and the Victorian Government.

15

\section{Notes and references}

${ }^{a}$ Department of Mechanical \& Aerospace Engineering \& Division of Biological Engineering, Monash University, Clayton, Australia.

${ }^{b}$ Intelligent Polymer Research Institute, University of Wollongong, $20 \quad$ Australia.

${ }^{c}$ School of Applied Science, RMIT University, Australia.

${ }^{d}$ Melbourne Centre for Nanofabrication, Australia

"Corresponding author, Tel: +61 39925 2660; E-mail: peggy.chan@rmit.edu.au

25

$\dagger$ Electronic Supplementary Information (ESI) available: See DOI: $10.1039 / \mathrm{b} 000000 \mathrm{x} /$

301 N. Xu, T. Papagiannakopoulos, G. Pan, J. A. Thomson and K. S. Kosik, Cell, 2009, 137, 647-658.

2 Z. Du, H. Cai, Z. Ye and W.-S. Tan, Journal of Biotechnology, 2012, 164, 211-219.

3 C. A. V. Rodrigues, T. G. Fernandes, M. M. Diogo, C. L. da Silva

35 and J. M. S. Cabral, Biotechnology Advances, 2011, 29, 815-829.

4 T. Liu, Comprehensive Biotechnology (2nd edition), 2011, 5, 389396.

5 J. Chen and D. Pei, Nature Methods, 2012, 9, 449-451.

6 G. C. Reilly and A. J. Engler, Journal of Biomechanics, 2010, 43, 5562.

7 A. J. Engler, S. Sen, H. L. Sweeney and D. E. Discher, Cell, 2006, 126, 677-689.

8 E. Cimetta, E. Figallo, C. Cannizzaro, N. Elvassore and G. VunjakNovakovic, Methods, 2009, 47, 81-89.

${ }_{45} 9$ L. Y. Yeo, H.-C. Chang, P. P. Y. Chan and J. R. Friend, Small, 2011, 7, 12-48.

10 V. Compan, A. Lopez-Alemany, E. Riande and M. F. Refojo, Biomaterials, 2004, 25, 359-365.

11 F. Abbasi, H. Mirzadeh and A. A. Katbab, Polymer International, 50 2001, 50, 1279-1287.

12 M. L. van Poll, F. Zhou, M. Ramstedt, L. Hu and W. T. S. Huck, Angewandte Chemie-International Edition, 2007, 46, 6634-6637.

13 H. Yan, B. Zhang and H. Wu, Electrophoresis, 2008, 29, 1775-1786.

14 N. R. Glass, R. Tjeung, P. Chan, L. Y. Yeo and J. R. Friend, Biomicrofluidics, 2011, 5, 36501-365017.

15 Z. Yue, X. Liu, P. J. Molino and G. G. Wallace, Biomaterials, 2011, 32, 4714-4724.
16 A. T. Reza and S. B. Nicoll, Acta Biomaterialia, 2010, 6, 179-186.

17 N. A. Ramli and T. W. Wong, International Journal of 60 Pharmaceutics, 2011, 403, 73-82.

18 C. K. Ryan and H. C. Sax, American Journal of Surgery, 1995, 169, 154-160.

19 J. Ma, Y. Xu, B. Fan and B. Liang, European Polymer Journal, 2007, 43, 2221-2228.

6520 M. A. Lalountas, K. D. Ballas, C. Skouras, C. Asteriou, T. Kontoulis, D. Pissas, A. Triantafyllou and A. K. Sakantamis, American Journal of Surgery, 2010, 200, 118-123.

21 A. J. García and D. Boettiger, Biomaterials, 1999, 20, 2427-2433.

22 H. Shin, S. Jo and A. G. Mikos, Biomaterials, 2003, 24, 4353-4364.

7023 L. S. Wang, J. E. Chung, P. P. Y. Chan and M. Kurisawa, Biomaterials, 2010, 31, 1148-1157.

24 W. Albrecht, B. Seifert, T. Weigel, M. Schossig, A. Hollander, T. Groth and R. Hilke, Macromolecular Chemistry and Physics, 2003, 204, 510-521.

7525 T. Goda, T. Konno, M. Takai, T. Moro and K. Ishihara, Biomaterials, 2006, 27, 5151-5160.

26 M. Ferrando, A. Rozek, M. Zator, F. Lopez and C. Guell, Journal of Membrane Science, 2005, 250, 283-293.

27 T. Lu, X. Chen, Q. Shi, Y. Wang, P. Zhang and X. Jing, Acta

80 Biomaterialia, 2008, 4, 1770-1777.

28 J. Wei, L. Yan, X. Hu, X. Chen, Y. Huang and X. Jing, Colloids and Surfaces B-Biointerfaces, 2011, 83, 220-228.

29 S. Hemmilä, J. V. Cauich-Rodríguez, J. Kreutzer and P. Kallio, Applied Surface Science, 2012, 258, 9864-9875.

8530 M. Farrell and S. Beaudoin, Colloids and Surfaces B-Biointerfaces, 2010, 81, 468-475.

31 H. T. Kim and O. C. Jeong, Microelectronic Engineering, 2011, 88, 2281-2285.

32 P. F. Gratzer and J. M. Lee, Journal of Biomedical Materials 90 Research, 2001, 58, 172-179.

33 L. Bertilsson, H. Elwing, B. Liedberg, O. Larm, J. Risenfeld and E. Scholander, Molecular Engineering, 1991, 1, 49-57.

34 D. Bodas and C. Khan-Malek, Sensors and Actuators B-Chemical, 2007, 123, 368-373.

9535 L. H. Zhao, J. Lee and P. N. Sen, Sensors and Actuators a-Physical, 2012, 181, 33-42.

36 T. Mogues, J. Z. Li, J. Coburn and D. J. Kuter, Journal of Immunological Methods, 2005, 300, 1-11.

37 S. M. Moghimi, Biochimica Et Biophysica Acta-Molecular Cell 100 Research, 2002, 1590, 131-139.

38 J. Hu, S. J. Li and B. L. Liu, Biochemical Engineering Journal, 2005, 23, 259-263.

39 Y. L. Jeyachandran, J. A. Mielczarski, E. Mielczarski and B. Rai, Journal of Colloid and Interface Science, 2010, 341, 136-142.

10540 Y. L. Jeyachandran, E. Mielezarski, B. Rai and J. A. Mielczarski, Langmuir, 2009, 25, 11614-11620.

41 J. Y. Yoon, H. Y. Park, J. H. Kim and W. S. Kim, Journal of Colloid and Interface Science, 1996, 177, 613-620.

42 C. Chang and L. Zhang, Carbohydrate Polymers, 2011, 84, 40-53.

11043 J. D. Ziebarth and Y. Wang, Biomacromolecules, 2010, 11, 29-38.

44 R. G. Chapman, E. Ostuni, S. Takayama, R. E. Holmlin, L. Yan and G. M. Whitesides, Journal of the American Chemical Society, 2000, 122, 8303-8304. 
45 V. Tangpasuthadol, N. Pongchaisirikul and V. P. Hoven, Carbohydrate Research, 2003, 338, 937-942.

46 H. Kurosawa, Journal of Bioscience and Bioengineering, 2007, 103, 389-398.

${ }_{5} 47$ B. Valamehr, S. J. Jonas, J. Polleux, R. Qiao, S. Guo, E. H. Gschweng, B. Stiles, K. Kam, T.-J. M. Luo, O. N. Witte, X. Liu, B. Dunn and H. Wu, Proceedings of the National Academy of Sciences of the United States of America, 2008, 105, 14459-14464.

48 I. Meyvantsson and D. J. Beebe, in Annual Review of Analytical $10 \quad$ Chemistry, 2008, pp. 423-449. 


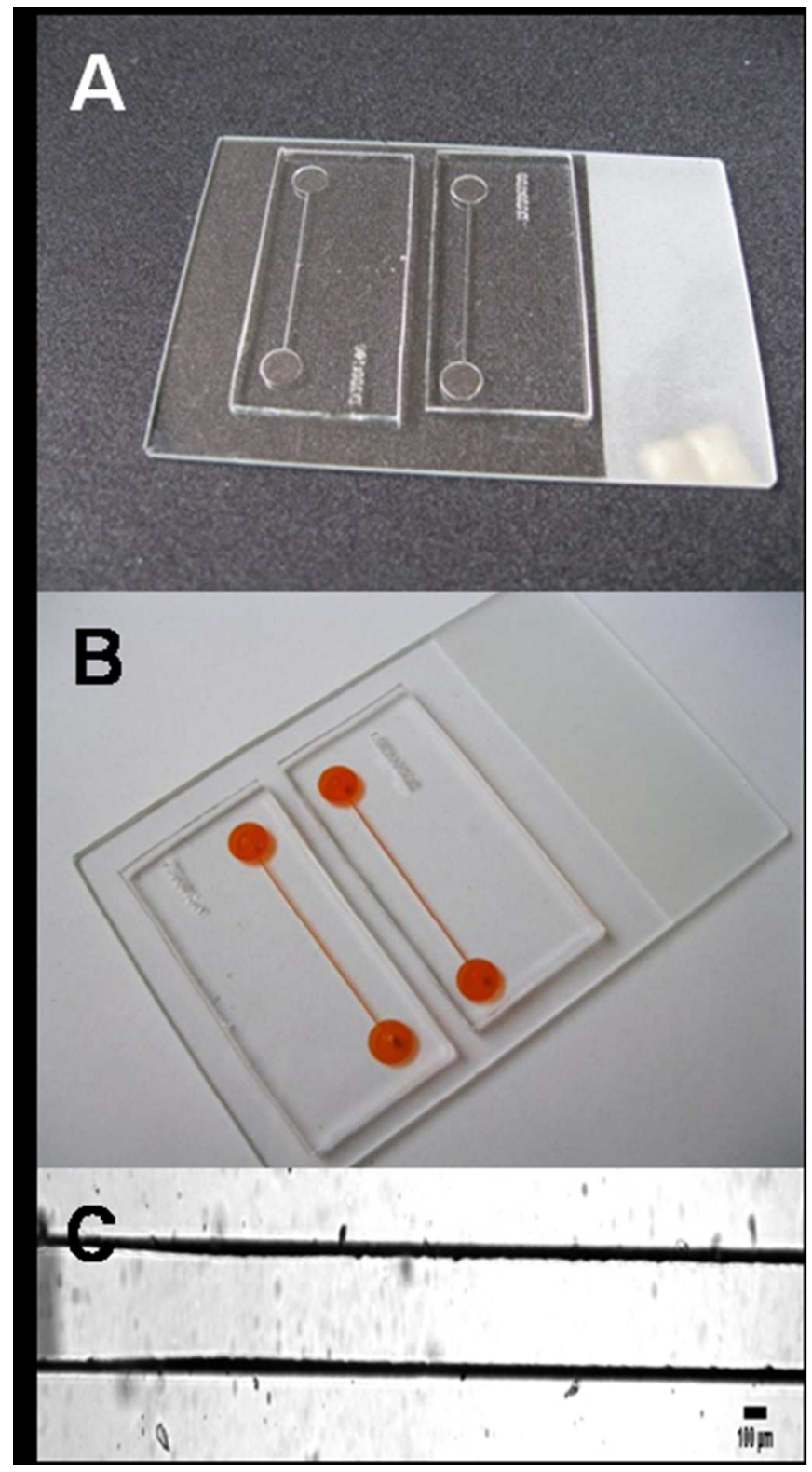

Fig. 1 Photo of (A) PDMS micro-bioreactor, (B) food-dye filled micro-bioreactor device showing inlets, outlets and microchannels, $(C)$ enlarged bright field view of microchannel, photo taken under a optical microscope (scale bar $=100 \mu \mathrm{m})$. $65 \times 119 \mathrm{~mm}(150 \times 150 \mathrm{DPI})$ 


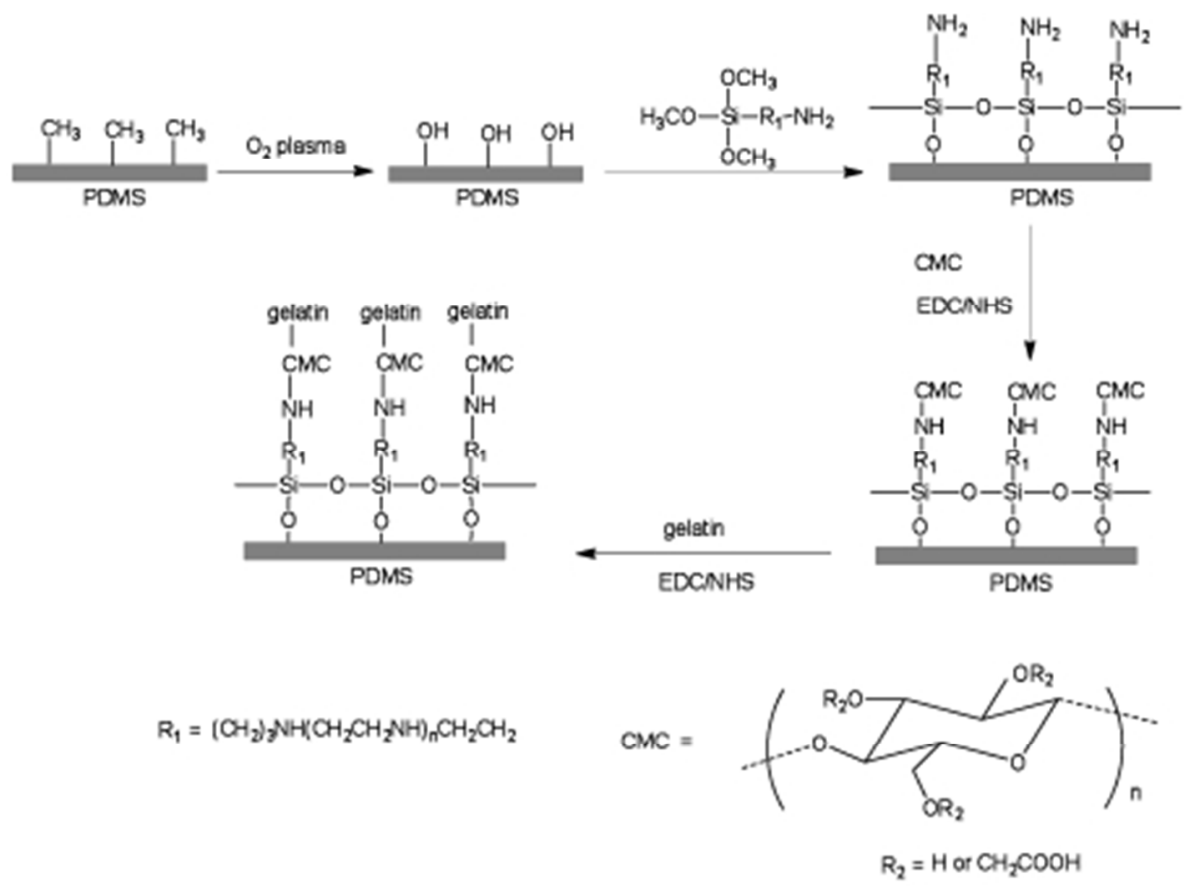

Fig. 2 Schematic illustration of the surface functionalization procedure. $160 \times 118 \mathrm{~mm}(72 \times 72 \mathrm{DPI})$ 


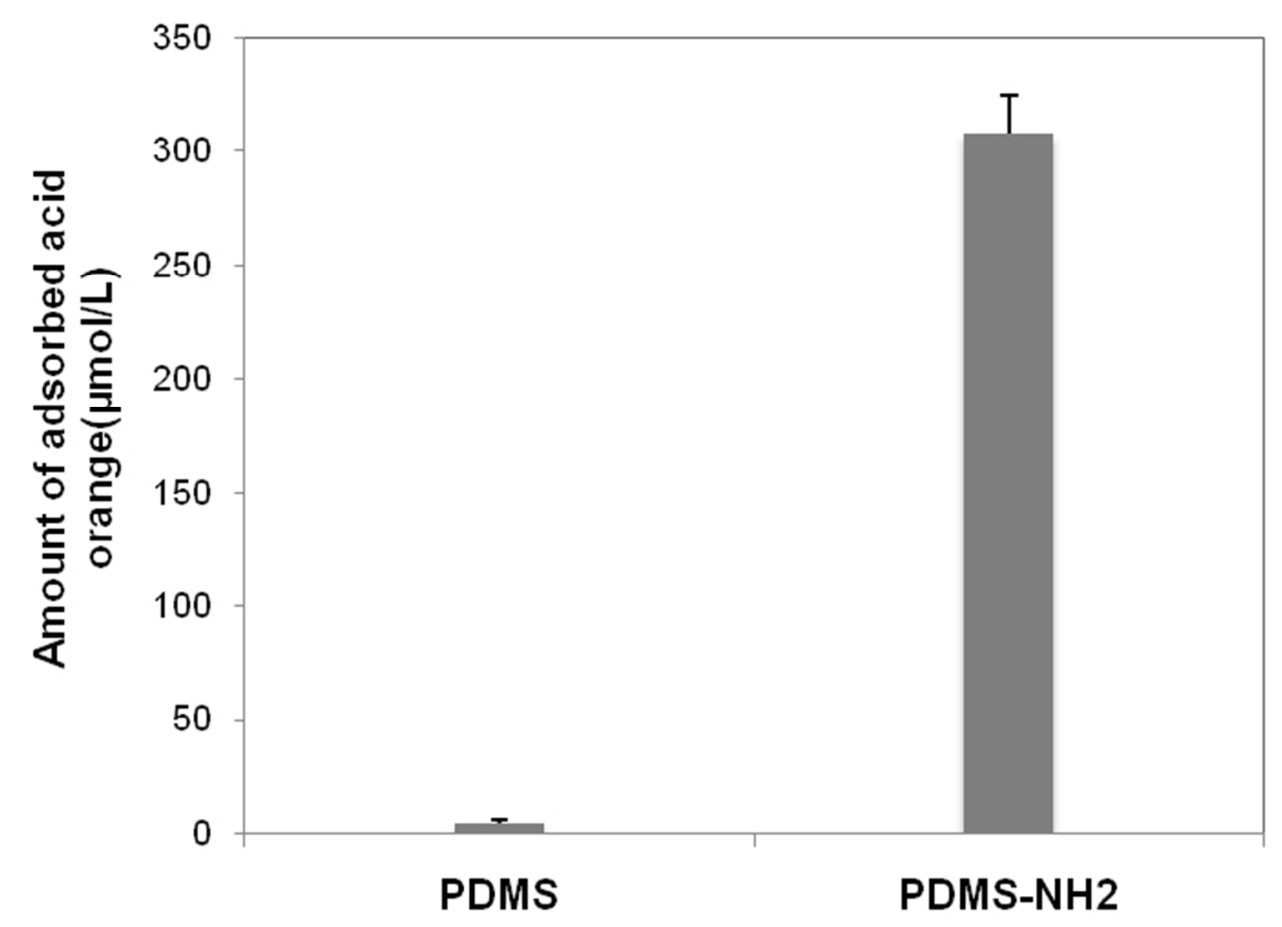

Fig. 3 Quantification of surface amine on native PDMS and PDMS- $\mathrm{NH}_{2}$ by measuring the amount of adsorbed acid orange.

$251 \times 178 \mathrm{~mm}$ (72 x 72 DPI) 


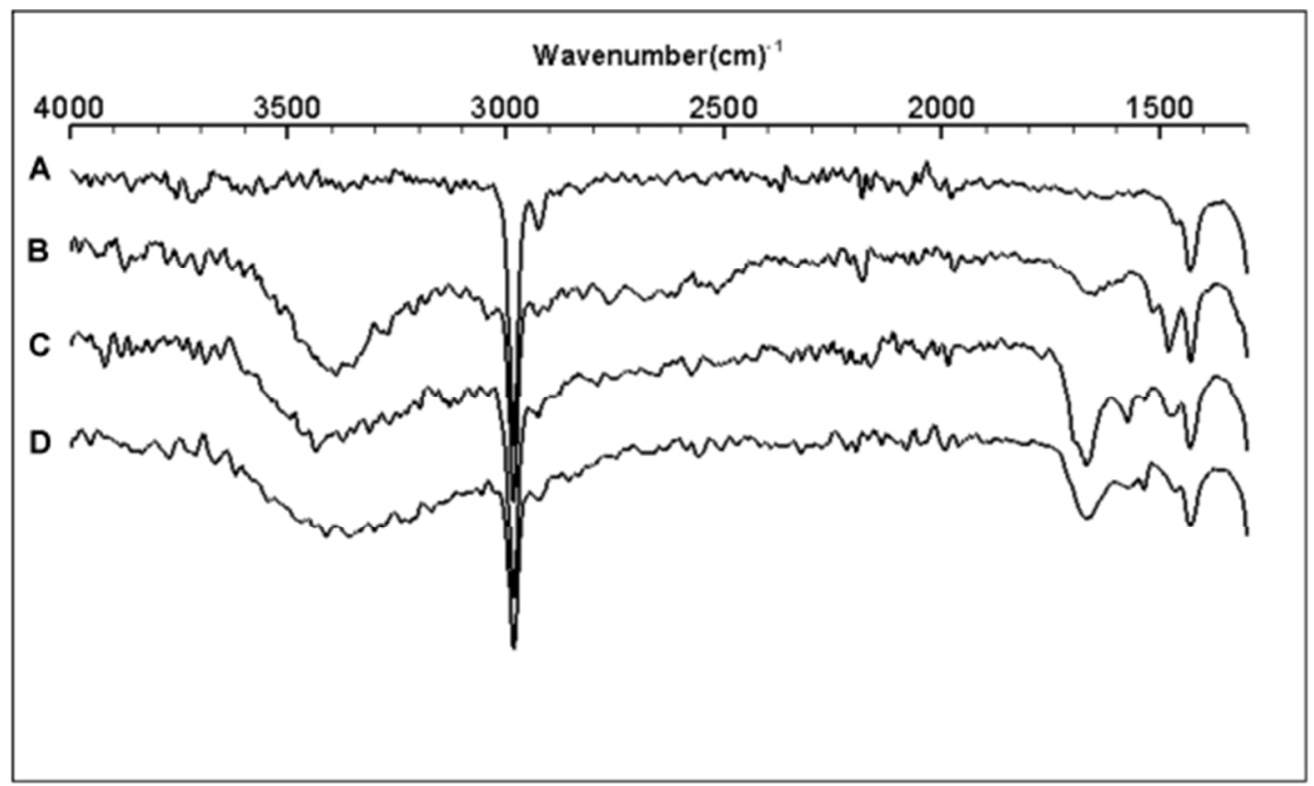

Fig. 4 FTIR spectra of (a) PDMS, (b) PDMS-NH ${ }_{2}$, (c) PDMS-NH-CMC, and (d) PDMS-NH-CMC-GEL. $201 \times 120 \mathrm{~mm}(72 \times 72 \mathrm{DPI})$ 
A

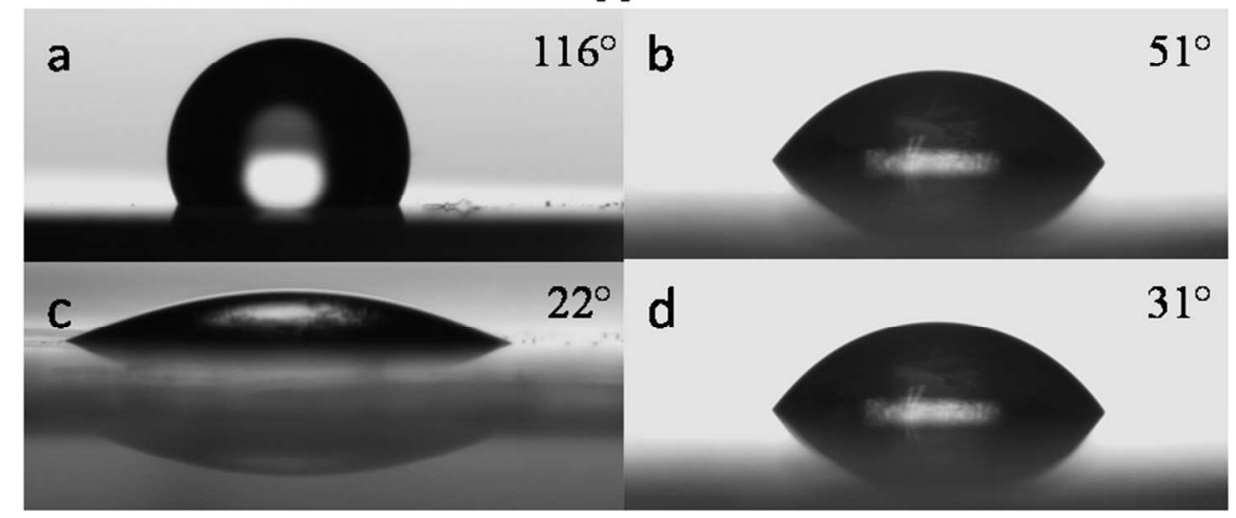

B

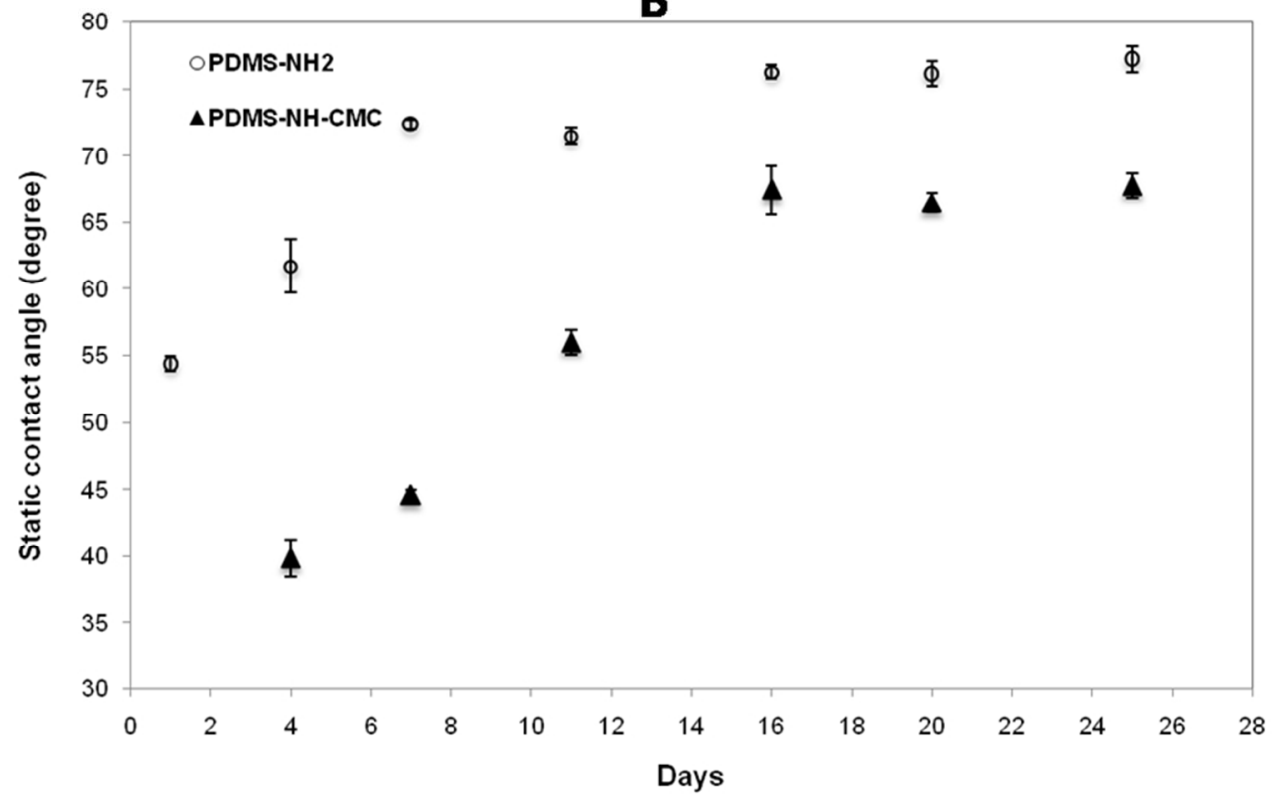

Fig. 5 (A) Static water contact angle of (a) PDMS, (b) PDMS-NH2, (c) PDMS-NH-CMC, and (d) PDMS-NH-

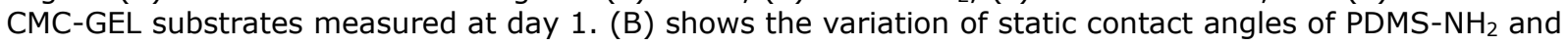
PDMS-NH- CMC as a function of the storage time in air. $155 \times 172 \mathrm{~mm}(150 \times 150 \mathrm{DPI})$ 


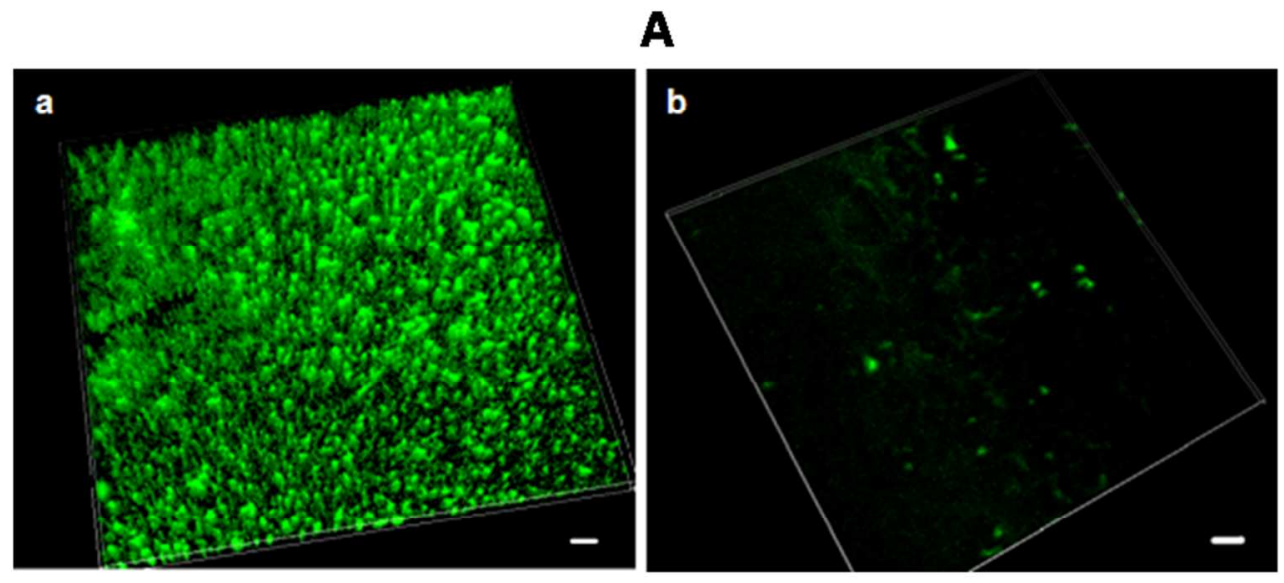

B

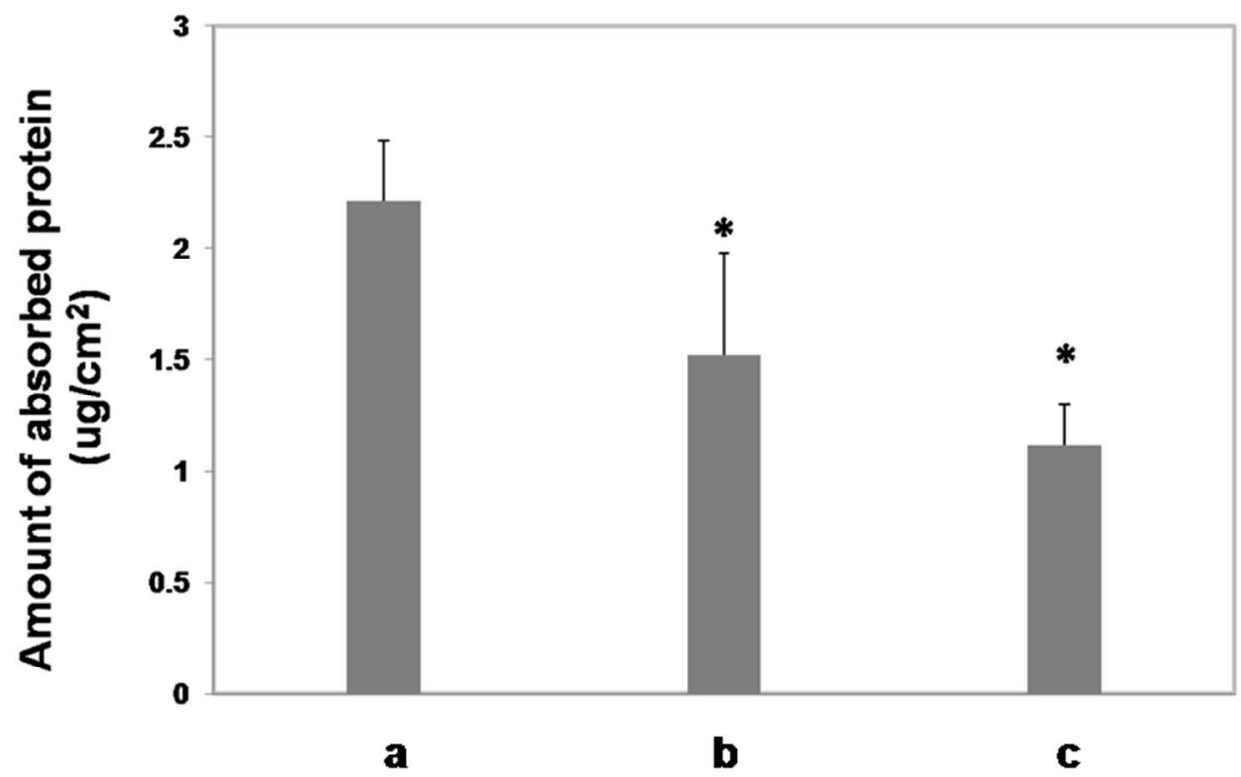

Fig. 6 (A) Confocal microscopy images showing BSA-FITC adsorption on PDMS and PDMS-NH-CMC. (scale bar $=100 \mu \mathrm{m})$. (B) shows the influence of surface modification on BSA adsorption on (a) PDMS, (b) PDMS$\mathrm{NH}_{2}$, and (c) PDMS-NH-CMC substrates. Data presented as average values \pm standard deviation $(* \mathrm{p}<0.05)$. $149 \times 171 \mathrm{~mm}(150 \times 150 \mathrm{DPI})$ 


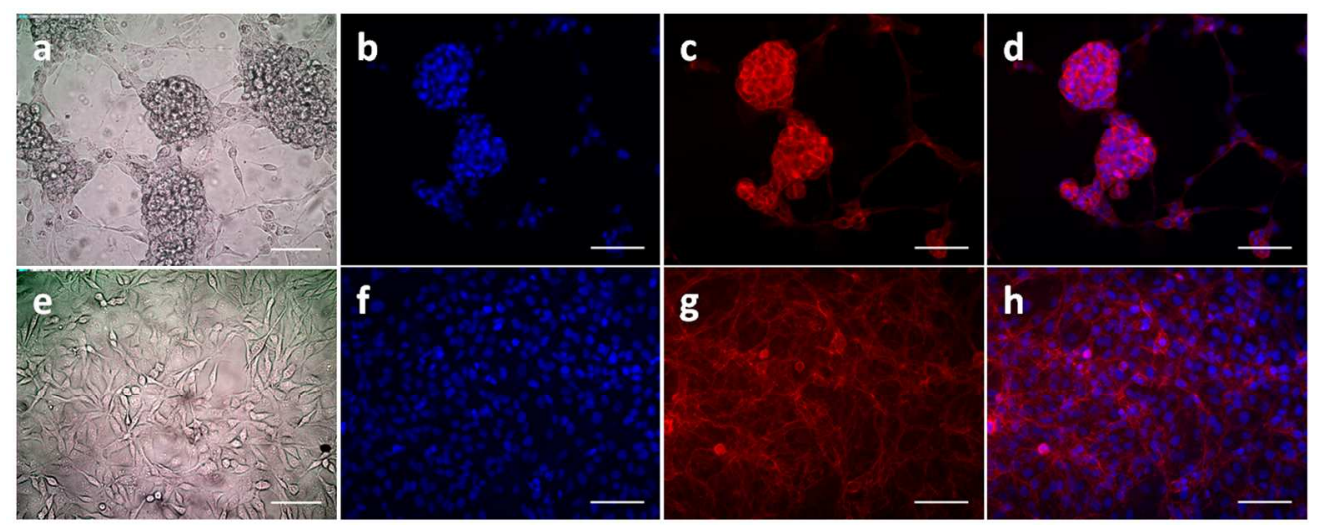

Fig. 7. Bright field and fluorescence microscopy images of MDA-MB-231 cells cultured on (a,b,c,d) PDMS, and $(e, f, g, h)$ PDMS-NH-CMC-GEL. (a,e) Bright field images. (b, f) fluorescence microscopy images show cell nuclei stained by DAPI (blue), (c, g) F-actin stained by Red $(-X$ Phalloidin (red), (d, h) overlay of DAPI and Red $(X) X$ Phalloidin fluorescence channels. (scale bar $=100 \mu \mathrm{m})$. $223 \times 88 \mathrm{~mm}(150 \times 150 \mathrm{DPI})$ 


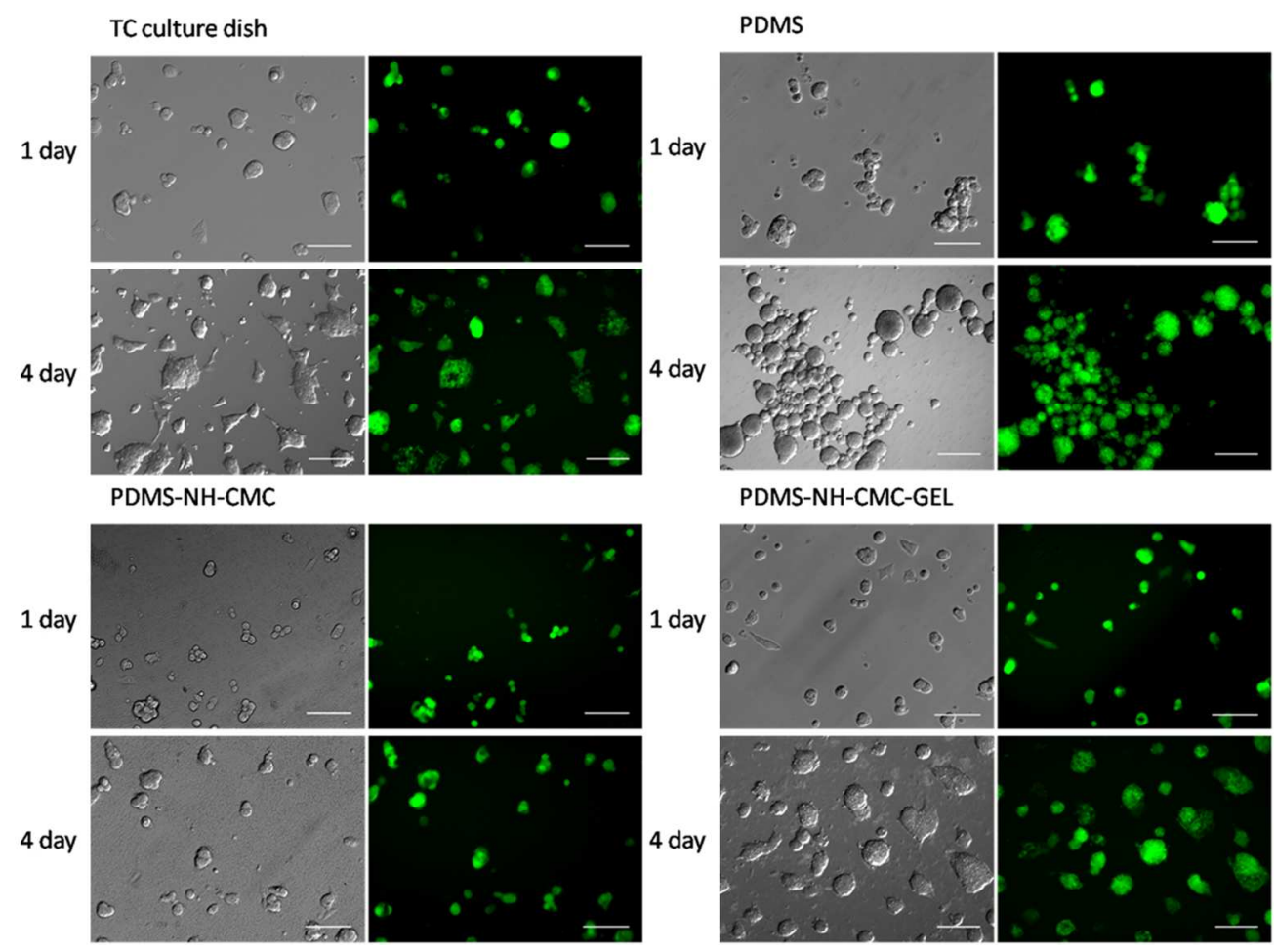

Fig. 8. Phase contrast images of Oct4b2 cells cultured on different substrates. Fluorescence microscopy images show Oct-GFP expression of Oct4b2 cells (scale bar for day one is $100 \mu \mathrm{m}$ and for day 4 is $250 \mu \mathrm{m}$ ). $188 \times 140 \mathrm{~mm}(150 \times 150 \mathrm{DPI})$ 

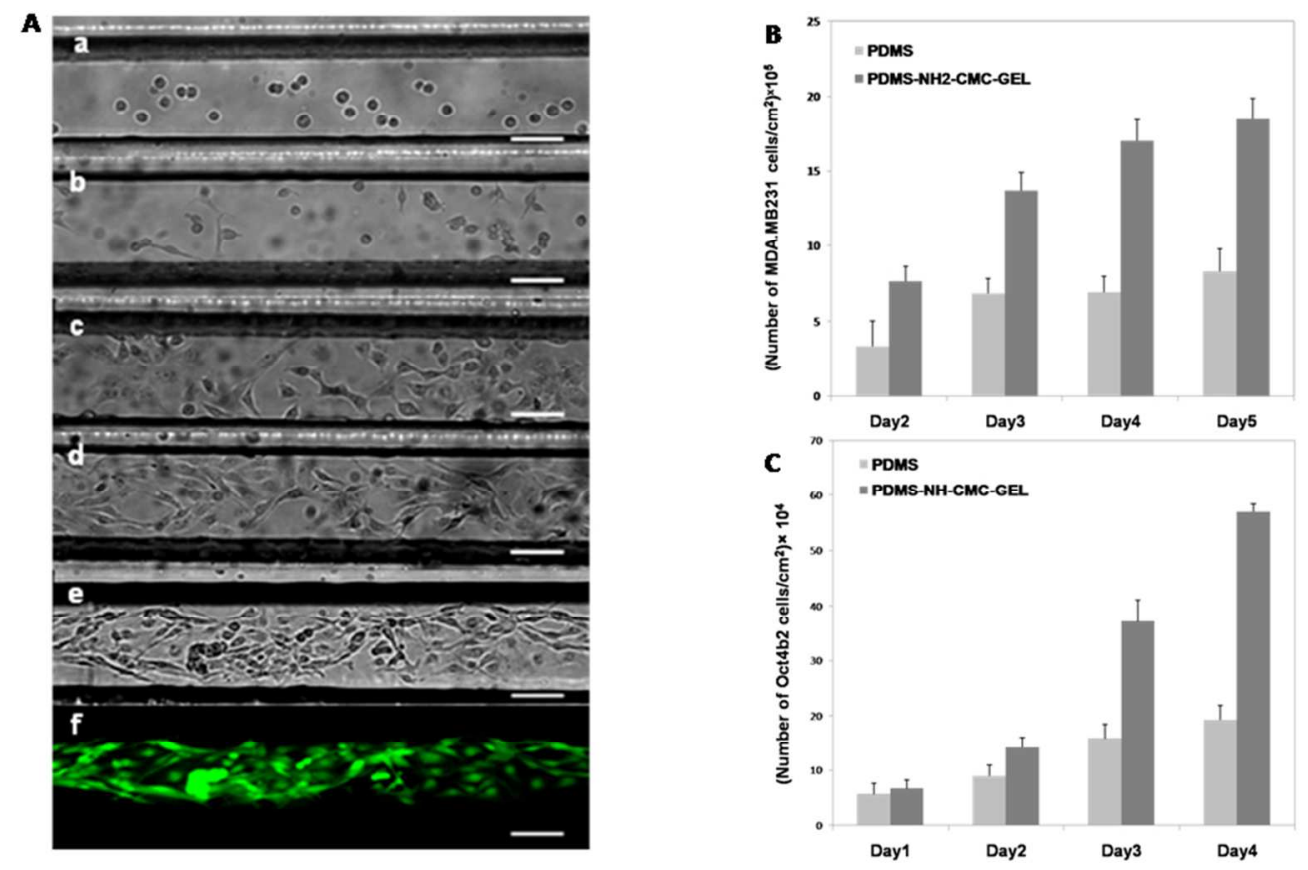

Fig. 9 (A) Phase contrast images of MDA-MB-231 cells cultured in PDMS-NH-CMC-GEL functionalized microchannels after (a) $0 \mathrm{hr}$, (b) $4 \mathrm{hr}$, (c) 1 day, (d) 3 days, and (e) 4 days after cell seeding. (f) Fluorescence microscopy image of live cells stained by Calcein AM (green) after 4 days. (scale bar $=100$ $\mu \mathrm{m})$. (B) shows the proliferation of (a) MDA-MB-231 cells, and (C) Oct4b2 cells on PDMS and PMDS-NHCMC-GEL substrates was monitored over a period of four days. $156 \times 105 \mathrm{~mm}(150 \times 150 \mathrm{DPI})$ 
Graphical and textual abstract for the contents pages
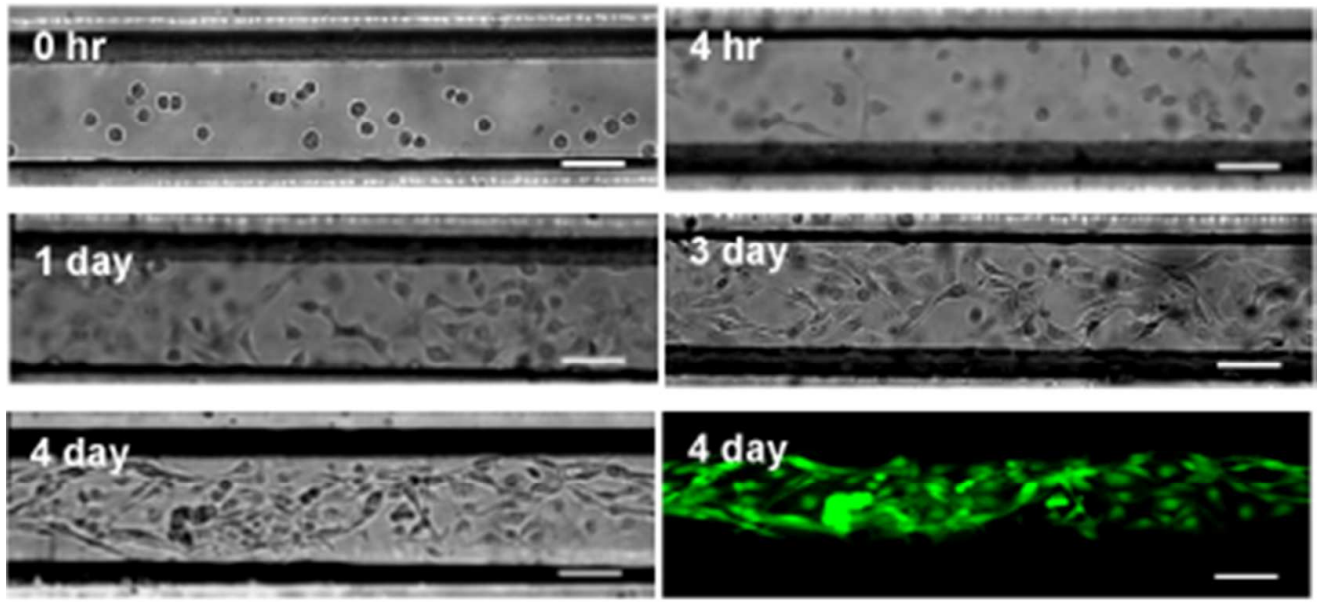

This study presents a method to surface functionalize a micro-bioreactor to enable cell adhesion and resistance to non-specific protein adsorption. 